\begin{tabular}{|c|l|}
\hline Title & Sub-critical crack growth in anisotropic rock \\
\hline Author(s) & Nara, Y.; Kaneko, K. \\
\hline Citation & $\begin{array}{l}\text { International Journal of Rock Mechanics and Mining Sciences, 43(3), 437-453 } \\
\text { https://doi.org/40.1016/.jirmms.2005.07.008 }\end{array}$ \\
\hline Issue Date & 2006-04 \\
\hline Doc URL & http://hdl.handle.net/2115/16988 \\
\hline Type & article (author version) \\
\hline File Information & IJRM 43 3.pdf \\
\hline
\end{tabular}

Instructions for use 


\title{
Subcritical crack growth in anisotropic rock
}

\author{
Y. NARA ${ }^{*}$ and K. KANEKO ${ }^{b}$
}

a. Ph.D., Division of Environment and Resources Engineering, Graduate School of Engineering, Hokkaido University, Sapporo 060-8628, JAPAN

(*Corresponding author: E-mail nara@eng.hokudai.ac.jp, FAX 011-706-6325)

b. Professor, Division of Environment and Resources Engineering, Graduate School of Engineering, Hokkaido University, Sapporo 060-8628, JAPAN

Abstract

In this study, subcritical crack growth in granite was investigated experimentally using the Double Torsion (DT) test. The orthorhombic elastic properties of granite, caused by the preferred orientation of pre-existing microcracks, were used to estimate the crack velocities and stress intensity factors. The results showed that the crack velocity in granite varied depending on its direction of propagation. The fastest crack velocities for a given vapor pressure were obtained when the crack propagated in the direction parallel to the plane in which the crack density of the pre-existing 
microcracks was the highest. Hence, subcritical crack growth in granite is affected by pre-existing microcracks. It was shown that the crack velocity was high when the water vapor pressure was high. From the results obtained under different temperatures and water vapor pressures, values of the activation energy for subcritical crack growth were estimated. The crack velocity under any given temperature, water vapor pressure, and stress intensity factor can be predicted theoretically if the activation energy is accurately estimated. The activation energy in granite is higher than that in glass. Cracks propagate in a straight line in glass, whereas they do not form a straight line in rocks due to the heterogeneity. The total length and surface area of cracks in rocks are therefore greater than those of straight cracks in glass. The larger activation energies in rocks are due to their heterogeneity.

Keywords: subcritical crack growth, stress corrosion, Double Torsion test, granite, anisotropy, activation energy 


\section{Introduction}

Knowledge of the time-dependent properties of rock behaviors, such as

ductile or brittle deformation, is essential to ensure the long-term stability of structures in rock mass, such as an underground power plant or a cavern for storing liquefied petroleum or natural gas (LPG or LNG). Subcritical crack growth is one of the main causes of time-dependent behavior in rocks. Under low homologous temperatures and atmospheric pressure, stress corrosion is the main mechanism for subcritical crack growth in rocks [1]. In the case of silicate materials, stress corrosion is a weakening process due to a chemical reaction between the strong siloxane bond structure near the crack tip strained by the tensilestress and the corrosive agent in the environment. The corrosive agent is likely to be water [1-3], which is transported to the crack tip.

The authors have previously investigated subcritical crack growth in andesite in air [4]. The study demonstrated that the crack velocity increased with increasing temperature and water vapor pressure. In addition, the authors estimated the activation energy for crack growth and suggested 
means to predict the crack velocity in andesite under various environmental and stress conditions. However, it was impossible to discuss the effects of rock fabrics and to apply the results for Kumamoto andesite to anisotropic rocks, because Kumamoto andesite was approximately isotropic [5] and the crack velocity was also isotropic [4].

Crack growth behavior may be affected by the anisotropy of the material. Anisotropy of the physical properties in rocks can be caused by the preferred orientation of pre-existing microcracks, the bedding plane, the orientation of rock-forming minerals, and so on. In the case of granite, the preferred orientation of pre-existing microcracks is considered to be the main source of anisotropy. For example, Douglass and Voight [6] reported, using Barre granite and Stanstead granite, that the maximum preferred orientations of microcracks were directly related to the direction of the lowest Young's modulus, and the directions of minimum compressive and tensile strength were related to the preferred orientation of microcracks. Peng and Johnson [7] reported that microcracks in Chelmsford granite were preferentially oriented along three mutually perpendicular planes and affected the physical properties of the granite in terms of the Brazilian tensile strength, the 
uniaxial compressive strength, and the Young's modulus. Birch [8, 9] and Thill et al. [10] described the anisotropic properties of elastic wave velocity in granite. Kudo et al. [11] examined thin sections and reported that microcracks in Oshima granite had a remarkable preferred orientation parallel to the rift plane. Additionally, they reported that the P-wave velocity and the Brazilian tensile strength were anisotropic. The P-wave velocity was the lowest when the P-wave propagated perpendicular to the rift plane in which the most microcracks existed [11]. The Brazilian tensile strength was the lowest when the loading direction was parallel to the rift plane [11]. Sano et al. [12] concluded from microcrack observations and measurements of the elastic wave velocities that granite had orthorhombic elastic properties using Oshima granite, Barre granite, and Chelmsford granite.

For anisotropic materials, the anisotropy of the crack velocities in the subcritical range has been reported, for example, by Scholz [13] and Atkinson [14, 15] in quartz, by Henry et al. [16] in a slightly anisotropic marble, and by Sano and Kudo [17] in granite. It is important to consider the material anisotropy in crack propagation problems.

In this study, the anisotropic properties of subcritical crack growth in 
granite were analyzed from results obtained using the Double Torsion test and considering the orthorhombic elastic properties of the granite. An experiment was conducted under different water vapor pressures to determine the environmental dependency of subcritical crack growth. In particular, the effects of pre-existing microcracks and water vapor pressure were investigated quantitatively, and the relation of subcritical crack growth to rock fabrics and environmental conditions was determined. 
2. Crack velocity for subcritical crack growth

When the corrosive agent is water, stress corrosion in silicate materials can be expressed as follows $[1,18]$ :

$$
\equiv \mathrm{Si}-\mathrm{O}-\mathrm{Si} \equiv+\mathrm{H}_{2} \mathrm{O} \rightarrow \equiv \mathrm{Si}-\mathrm{OH}+\mathrm{HO}-\mathrm{Si} \equiv
$$

When stress corrosion controls the crack growth, the crack velocity, da/dt, is related to the stress intensity factor, $K_{\mathrm{I}}$, as

$$
\frac{\mathrm{d} a}{\mathrm{~d} t}=v_{1} P\left(\mathrm{H}_{2} \mathrm{O}\right) \exp \left(\frac{-E^{\ddagger}+\beta K_{\mathrm{I}}}{R T}\right)
$$

where $P\left(\mathrm{H}_{2} \mathrm{O}\right)$ is the water vapor pressure, $E^{*}$ is the stress free activation energy, $R$ is the gas constant, $T$ is the absolute temperature, and $v_{1}$ and $\beta$ are material constants [19-21]. The water vapor pressure, $P\left(\mathrm{H}_{2} \mathrm{O}\right)$, can be calculated from the following equation [22]:

$$
\left.\begin{array}{l}
P\left(\mathrm{H}_{2} \mathrm{O}\right)=e_{s} \times h \\
e_{s}=6.11 \times 10^{7.5(T-273.2) /(T-35.9)} \times 10^{2}
\end{array}\right\}
$$

where $e_{s}$ is the saturation water vapor pressure and $h$ is the relative humidity.

Charles [23] showed a different relation between $\mathrm{d} a / \mathrm{d} t$ and $K_{\mathrm{I}}$ for subcritical crack growth:

$$
\frac{\mathrm{d} a}{\mathrm{~d} t}=v_{2} K_{\mathrm{I}}^{n_{\mathrm{s}}} \exp \left(\frac{-E^{\ddagger}}{R T}\right)
$$


where $v_{2}$ and $n_{s}$ are constants. Especially, $n_{s}$ is called subcritical crack growth index [1]. This equation has been used by many researchers, because it is convenient to integrate and differentiate.

In this study, it is assumed that the energy barrier decreases with increasing stress. Therefore, Eq.(2) is mainly used to discuss the relation between $\mathrm{d} a / \mathrm{d} t$ and $K_{\mathrm{I}}$ for subcritical crack growth. The values of $n_{\mathrm{s}}$ determined using Eq.(4) will be shown in Appendix B. 


\section{Methodology}

3.1 Double Torsion method

3.1.1 Stress intensity factor and crack velocity

The Double Torsion (DT) test is one of several fracture mechanics testing methodsused to study subcritical crackgrowth. The shape of the DT specimen and the loading configuration are schematically shown in Fig. 1 . In this testing method, the stress intensity factor is independent of the crack length. Hence, the DT test is convenient when using opaque materials such as rocks for which crack length measurements are difficult.

There are three methods for obtaining the crack velocity in DT tests, each of which has a different loading procedure. The constant load (CL) method was used by Kies and Clark [24] for the original DT test. Two other methods, constant displacement rate (CDR) and load relaxation (RLX), were introduced by Evans [25]. In the RLX method, the displacement of the loading point is kept constant during the experiment and the load relaxation owing to crack growth is measured. Because the stress intensity factor is a function of the 
load and the crack growth rate is a function of the temporal load and decreasing rate of the load, the relation between the stress intensity factor and the crack growth rate can be obtained over a wide range of loads using a single experimental run. For this reason, the RLX method was adopted in this study.

Sano and Kudo [17] derived the equations of the stress intensity factor and the crack velocity for a DT specimen of the orthorhombic material assuming that the loading direction was parallel to the principal axes of the orthorhombic material. For the orthorhombic material, assuming that the directions of the coordinate axes and loading are defined as given in Fig. 1, the stress intensity factor, $K_{\mathrm{I}}$, and the crack growth rate, $\mathrm{d} a / \mathrm{d} t$, can be expressed as follows [17]:

$$
\begin{gathered}
K_{\mathrm{I}}=\left(\frac{3 P^{2} w_{m} s_{66}}{2 d^{3} d_{n}\left(2 s_{22}\left(\left(s_{11} s_{22}\right)^{1 / 2}+s_{12}+s_{66} / 2\right)^{1 / 2}\right)}\right)^{1 / 2}, \\
\frac{\mathrm{d} a}{\mathrm{~d} t}=\phi \frac{-2 S_{0} P_{0}(\mathrm{~d} P / \mathrm{d} t) d^{3}}{3 P^{2} s_{66} w_{m}}
\end{gathered}
$$

where $P$ is the load, $w_{m}$ is the moment arm, $d$ is the thickness of the DT specimen, $d_{n}$ is the reduced thickness of the specimen, $s_{i j}(i, j=1 \sim 6)$ is the compliance constant of the material, $P_{0}$ is the initial value of the load, $S_{0}$ is 
the initial value of the compliance of the DT specimen determined from the relation between the load and the displacement of the loading point, $\mathrm{d} P / \mathrm{d} t$ is the load relaxation rate, and $\phi$ is a constant that is dependent on the shape of the crack front. For glass and quartz, $\phi$ is approximately $0.2[14,26]$. Therefore, $\phi=0.2$ was used in this study. If the loading direction is different from that given in Fig. 1, the subscripts of $s_{i j}$ in Eqs.(5) and (6) must be transformed.

In order to assess subcritical crack growth in anisotropic materials using DT tests, estimates of the anisotropic elastic constants are required. The calculation procedure and evaluation method used to estimate the anisotropic elastic constants for granite are described in the Appendix A. 


\subsubsection{Specimen geometry}

It is important to consider the applicability of Eqs. (5) and (6), as these are approximate solutions based on a thin-plate assumption [17,26]. The size of the DT specimens has to satisfy the condition [27-29]

$$
12 d \leq W \leq L / 2
$$

where $L$ and $W$ are the length and the width of the DT specimen, respectively. In addition, the stress intensity factor $K_{I}$ is independent of the crack length $a$ over the range [30]

$$
0.55 W<a<L-0.65 W
$$

Recently, Ciccoti et al. [31-34] reported an analytical approach to the RLX method for DT tests using a finite element analysis. They express the corrective factor of the specimen compliance to consider the non-linear terms of the dependence of the compliance o the crack length in a DT specimen [31, 32]. Additionally, based on their results, they used thicker specimen $(W: d=$ 8: 1) than those recommended by Evans et al. [27] or Atkinson [28], [33, 34]. Taking into account these restrictions, the size of the specimens in this study shown in Fig. 1 was set to the width $W=45 \mathrm{~mm}$, the thickness $d=3 \mathrm{~mm}$, the reduced thickness $d_{n}=2 \mathrm{~mm}$, and the length $L=140 \sim 170 \mathrm{~mm}$. The DT 
specimen used in this study had a single rectangular guide groove on the upper plane (see Fig. 1). Hence, the dimensions of the DT specimen are in the recommended range for the DT tests. The width of the guide groove was $1 \mathrm{~mm}$ for Oshima granite and Westerly granite, and $3 \mathrm{~mm}$ for Inada granite. The initial crack length, $a_{0}$, was $25 \mathrm{~mm}$, and data measured when the crack length ranged between 25 and $80 \mathrm{~mm}$ were used for the analyses. 


\subsection{Rock types}

Westerly granite, Oshima granite, and Inada granite were used for the DT

tests. In granite, two sets of preferred orientation of pre-existing microcracks were usually found [12, 35-37]. Based on the microscopic observation on thin sections of granites, Sano et al. [12] concluded that most of the microcracks in granites were approximately parallel to each other within the rift plane, secondary orientation of the microcracks was almost perpendicular to the rift plane, and typical granites had orthorhombic elasticity associated with the preferred orientation of microcracks. Therefore, granties were treated as orthorhombic materials in this study.

The P-wave velocities in the three orthogonal directions of these types of granite rock are listed in Table 1 . The $\mathrm{P}-$ wave velocity measurement was conducted by the ultrasonic transmission method. In this study, the orthogonal directions are termed axis-1, -2 , and -3 in the order of the measured P-wave velocities. The planes normal to axis-1, -2 , and -3 are called plane-1, -2 , and -3 , respectively. From Table 1, it is clear that the anisotropy of the P-wave velocity is small for Westerly granite and large for Inada 
granite.

Estimated values for the crack density of pre-existing microcracks and the elastic compliance are shown in Table 2. These values were determined from the new self consistent scheme [38,39] as described in the Appendix A. In the table, $\Phi_{0}$ is the crack density of randomly oriented microcracks, and $\Phi^{\prime}{ }_{2}$ and $\Phi^{\prime}{ }_{3}$ are the crack densities of cracks oriented normal to axis-2 and axis-3, respectively. Therefore, most microcracks are normal to axis-3, that is, parallel to plane-3.

The DT specimens were prepared taking the crack propagation and opening directions into account, as shown in Fig. 2. In the $1 \cdot 2$-specimen, for example, the crack propagates in the direction parallel to axis-1 and opens parallel to axis-2. 
3.3 Description of the experiment

\subsubsection{Testing apparatus}

A schematic illustration of the DT testing apparatus is shown in Fig. 3 .

This is the same apparatus as used by Nara and Kaneko [4]. The applied load was measured using a load cell with an accuracy of $0.04 \mathrm{~N}$. The displacement of the loading point was measured using two displacement transducers with an accuracy of $0.1 \mu \mathrm{m}$. The crack growth was monitored using a digital microscope placed under the specimen.

The testing apparatus was placed in a temperature- and humidity-controlled room. The temperature and relative humidity were kept constant within $0.1 \mathrm{~K}$ between 283 and $353 \mathrm{~K}$ and within $1 \%$ between 40 and $75 \%$, respectively. 


\subsubsection{Experimental conditions}

All of the experiments were performed under the same loading conditions while ensuring that the crack opened as wide as possible in the specimen. The displacement of the loading points was set to obtain a value of the initial load $P_{0}$ that corresponded to the stress intensity factor at which the crack propagated dynamically when the loading points were moved to the setting points [4]. In this study, fracture toughness measurements of granite [40-42] were used to determine the displacement of the loading points.

Based on the above preliminary considerations, the loading points were rapidly moved $0.24 \mathrm{~mm}$ after the $12 \sim 15 \mathrm{~N}$ preload was applied, which corresponded to $15 \sim 25 \%$ of the maximum load, so that $P_{0}$ approached a value corresponding as closely as possible to the fracture toughness. For the 1・3-specimen and 2•3-specimen for Inada granite, the displacement of the loading points was adjusted to $0.23 \mathrm{~mm}$ because the specimens often broke when a displacement of $0.24 \mathrm{~mm}$ was used.

The DT tests were conducted under two atmospheric conditions: one with a temperature and humidity of $284.1 \mathrm{~K}$ and $44 \pm 1 \%$ (condition A), and the other with a temperature and humidity of $329.7 \mathrm{~K}$ and $73 \pm 1 \%$ (condition B). The 
water vapor pressure was $570 \mathrm{~Pa}$ for condition A and $12.3 \mathrm{kPa}$ for condition B.

The water vapor pressure was determined using Eq. (3) by measuring the temperature and the relative humidity. 


\subsubsection{Experimental procedure}

The experimental procedure was the same as that of Nara and Kaneko [4].

First, specimen precracking was performed. For the specimen precracking, the load was slowly applied to the specimen while occasionally fixing the displacement of the loading points. In this stage, crackgrowth was monitored by using a digital microscope. The load was rapidly decreased when the crack length reached $25 \mathrm{~mm}$. After precracking, the temperature and humidity of the testing room were set and held constant. The rock specimen was exposed to the testing environment for $20 \mathrm{~h}$ before the DT test was performed. DT test was then conducted by the RLX method. A preload was slowly applied to the specimen, and then a large displacement was rapidly applied to the loading points of the specimen and held constant throughout the test. 


\section{Experimental results}

4.1 Anisotropy of $K_{\mathrm{I}}-\log (\mathrm{d} a / \mathrm{d} t)$ relations in granite

The relations between $K_{\mathrm{I}}$ and $\log (d a / d t)\left(K_{\mathrm{I}}-\log (\mathrm{d} a / \mathrm{d} t)\right.$ relation $)$ for Westerly granite, Oshima granite, and Inada granite are shown in Figs. 4, 5, and 6, respectively. In these figures, the square, triangular, and circular symbols indicate the results obtained for the specimens, in which the cracks propagated parallel to plane-1, -2 , and -3 , respectively. $K_{\mathrm{I}}-\log (\mathrm{d} a / \mathrm{d} t)$ relations in Figs. 4-6 were ontained for condition A (the temperature was $284.1 \mathrm{~K}$ and the relative humidity was $44 \%$ ) and represented the crack growth due to stress corrosion [1]. The results demonstrated that $K_{\mathrm{I}}-\log (\mathrm{d} a / \mathrm{d} t)$ relations showed directional dependence. When the crack advanced parallel to plane-3, crack growth occurred with a lower stress level.

The results obtained by applying Eq. (2) to the experimental data for Westerly granite, Oshima granite, and Inada granite are shown in Tables 3 , 4 , and 5 , respectively. In these tables, $\alpha$ can be expressed by the following equation, which was obtained by arranging Eq. (2): 


$$
\ln \left(\frac{\mathrm{d} a}{\mathrm{~d} t}\right)=\alpha+\frac{\beta}{R T} K_{\mathrm{I}} \quad\left(\because \alpha=\ln v_{1}+\ln P\left(\mathrm{H}_{2} \mathrm{O}\right)-\frac{E^{\ddagger}}{R T}\right)
$$

The value of $\alpha$ corresponds to the crack velocity at $K_{\mathrm{I}}=0$. The experimental scatter of this value becomes large in results obtained over a limited range of $K_{\mathrm{I}}$. The stress intensity factor at $\mathrm{d} a / \mathrm{d} t=10^{-5}[\mathrm{~m} / \mathrm{s}], K_{\mathrm{I}}\left(10^{-5}\right)$, and the crack velocity at $K_{\mathrm{I}}=1.8\left[\mathrm{MN} / \mathrm{m}^{3 / 2}\right]$, da/dt(1.8), are also listed in Tables 3 and 4 , while $K_{\mathrm{I}}\left(10^{-5}\right)$ and $\mathrm{d} a / \mathrm{d} t(1.4)$ are also listed in Table 5 , to provide quantitative comparisons. The numbers given in these tables are the mean values and standard deviations of three specimens of Westerly granite and Oshima granite, and of six or seven specimens of Inada granite.

It is clear that the smallest values of $K_{\mathrm{I}}\left(10^{-5}\right)$ and the largest values of $\mathrm{d} a / \mathrm{d} t(1.8)$ or $\mathrm{d} a / \mathrm{d} t(1.4)$ were obtained when the crack propagated parallel to plane-3, in which the crack density of pre-existing microcracks was the highest (see Fig. 2 and Table 2). These values for Oshima granite or Inada granite were consistent when the crack opening directions were the same. The results indicated that the crack opening direction strongly affected the subcritical crack growth behavior in granite. In addition, the reproducibility of the experimental results was greater for Westerly granite and Oshima granite than for Inada granite. 
From Tables 3-5, it is found that the degree of anisotropy of the $K_{\mathrm{I}}-\log (\mathrm{d} a / \mathrm{d} t)$ relation was larger for Inada granite and smaller for Westerly granite. For example, the anisotropy coefficients defined as (maximum-minimum)/average $[6,43]$ of the stress intensity factor $K_{\mathrm{I}}\left(10^{-5}\right)$ were $30.4 \%, 15.6 \%$, and $6.7 \%$ for Inada granite, Oshima granite, and Westerly granite, respectively.

The directional dependence of the constant $\beta$ was not clear. It is difficult to explain this result. More tests are necessary to collect additional measurements and improve the accuracy of the data. 
4.2 Environmental dependence of subcritical crack growth in granite

$K_{\mathrm{I}}-\log (\mathrm{d} a / \mathrm{d} t)$ relations of Westerly granite and Oshima granite obtained under different temperatures and humidity, i.e., different water vapor pressures, are shown in Figs. 7 and 8. In these figures, open symbols and solid symbols indicate the results obtained for condition A and condition B, respectively. Crack growth behavior was facilitated by higher water vapor pressure. The results of the DT tests for Westerly granite and Oshimagranite obtained under different water vapor pressures are listed in Tables 6 and 7 , respectively, which show average and standard deviation values. The values for condition A in Tables 6 and 7 are the same as those in Tables 3 and 4 . $K_{\mathrm{I}}\left(10^{-5}\right)$ decreased and $\mathrm{d} a / \mathrm{d} t(1.8)$ increased for the higher water vapor pressure. Thus the water vapor pressure strongly affected subcritical crack growth. 


\section{Discussion}

5.1 Anisotropic $K_{\mathrm{I}}-\mathrm{d} a / \mathrm{d} t$ relations

The results showed that $K_{\mathrm{I}}-\mathrm{d} a / \mathrm{d} t$ relations in granite are anisotropic. When the crack propagated parallel to plane-3, the stressintensity factor at a given crack velocity (for example, $K_{\mathrm{I}}\left(10^{-5}\right)$ ) was the smallest and the crack velocity at a given stress intensity factor (for example, da/dt(1.8) or da/dt(1.4)) was the largest. The reverse was true when the crack propagated parallel to plane- 1 . It is considered that scatterings of $K_{\mathrm{I}}-\log (\mathrm{d} a / \mathrm{d} t)$ relations shown in Figs. 4-6 are not caused by the difference of experimental techniques [44], because the experimental procedures and conditions were the same except for the specimen orientations. As described in Section 3.2 and shown in Table 2, granite has the preferred orientation of microcracks and most microcracks exist parallel to plane-3. It is worth investigating the effect of the preferred orientation of microcracks in the crack growth behavior.

The results of the DT tests showed that the degree of anisotropy of the $K_{\mathrm{I}}-\mathrm{d} a / \mathrm{d} t$ relation was different for each type of granite. The anisotropy 
coefficients, defined as (maximum-minimum)/average (see Section 4.1), of the stress intensity factor $K_{\mathrm{I}}\left(10^{-5}\right)$, were $30.4 \%, 15.6 \%$, and $6.7 \%$ for Inada granite, Oshima granite, and Westerly granite, respectively. From Table 1, the degree of anisotropy of the P-wave velocity was $14.4 \%, 8.5 \%$, and $2.3 \%$ for Inada granite, Oshima granite, and Westerly granite, respectively. In both cases, the anisotropy coefficient was the largest for Inada granite and smallest for Westerly granite. This suggests that the anisotropy of subcritical crack growth velocity correlates with that of the P-wave velocity.

To verify the correspondence between the subcritical crack growth and P-wave velocity anisotropies, the relation of the stress intensity factor at $\mathrm{d} a / \mathrm{d} t=10^{-5}[\mathrm{~m} / \mathrm{s}], K_{\mathrm{I}}\left(10^{-5}\right)$, and the $\mathrm{P}-\mathrm{wave}$ velocity in the direction normal to the crack plane is shown in Fig. 9. A positive correlation was obtained. The crack density of microcracks parallel to the crack plane has a large effect on the crackgrowth behavior because the P-wave velocity anisotropy is caused by the preferred orientation of the pre-existing microcracks.

Since the microcrack preferred orientation affects the crack growth behavior in granite, it may also affect $E^{*}$ and $v_{1}$. To determine the effect of pre-existing microcracks on crack growth behavior quantitatively, the 
relation between $\beta K_{I}\left(10^{-5}\right)$, which is the energy applied to the crack tip, and the density of pre-existing microcracks parallel to the crack propagation direction was investigated. The crack density of microcracks normal to axis-i can be expressed using the orientation distribution function $f(\boldsymbol{\eta})$ as follows:

$$
\Phi_{i}=\int_{\Delta \Omega\left(\eta_{i}\right)} f(\boldsymbol{\eta}) d \Omega
$$

where $\boldsymbol{\eta}$ is the unit normal vector of the microcrack on a hemisphere and $\Delta \Omega\left(\boldsymbol{\eta}_{i}\right)$ is the solid angle around axis-i. The function $f(\boldsymbol{\eta})$ can be expressed using the crack density of randomly oriented microcracks, $\Phi_{0}$, and that of microcracks oriented normal to axis- $2, \Phi_{2}^{\prime}$, and axis-3, $\Phi_{3}^{\prime}$, as follows:

$$
f(\boldsymbol{\eta})=\frac{\Phi_{0}}{2 \pi}+\Phi_{2}^{\prime} \delta\left(\boldsymbol{\eta}-\boldsymbol{\eta}_{2}\right)+\Phi_{3}^{\prime} \delta\left(\boldsymbol{\eta}-\boldsymbol{\eta}_{3}\right)
$$

where $\boldsymbol{\eta}_{2}$ and $\boldsymbol{\eta}_{3}$ are the unit vectors in the directions of axis-2 and -3 , respectively, and $\delta(\eta)$ is the Dirac delta function,

$$
\left.\begin{array}{rll}
\delta(\boldsymbol{\eta}) & =1 & (\boldsymbol{\eta}=0) \\
& 0 & (\boldsymbol{\eta} \neq 0)
\end{array}\right\}
$$

According to crack path observations [45, 46], crack growth occurs within $30^{\circ}$ of the crack propagation direction shown in Fig. 2 (see Fig. 10). Therefore, the above solid angle was set to $0.06 \times 2 \pi$ steradians (about $20^{\circ}$ ). The crack densities can be determined from 


$$
\left.\begin{array}{l}
\Phi_{1}=0.06 \times \Phi_{0} \\
\Phi_{2}=0.06 \times \Phi_{0}+\Phi^{\prime}{ }_{2} \\
\Phi_{3}=0.06 \times \Phi_{0}+\Phi^{\prime}{ }_{3}
\end{array}\right\}
$$

where $\Phi_{1}, \Phi_{2}$, and $\Phi_{3}$ are the crack densities of microcracks normal to axis-1, -2 , and -3 , respectively.

The relation between $\beta K_{I}\left(10^{-5}\right)$ and the crack density of microcracks normal to axis-i, $\Phi_{i}(i=1,2$ or 3$)$, is shown in Fig. 11. The figure indicates good correlations between $\beta K_{\mathrm{I}}\left(10^{-5}\right)$ and $\Phi_{i}: \beta K_{\mathrm{I}}\left(10^{-5}\right)$ decreased linearly with increasing $\Phi_{i}$. The crack growth resistance of granite was clearly dependent on the crack density of microcracks parallel to the crack propagation direction. Thus the anisotropy of $K_{I}-d a / d t$ relation was caused by the crack density and the preferred orientation of pre-existing microcracks.

When $\mathrm{d} a / \mathrm{d} t$ is $10^{-5} \mathrm{~m} / \mathrm{s}$, Eq. (9) can be transformed as

$$
\beta K_{\mathrm{I}}\left(10^{-5}\right)=R T\left(\ln 10^{-5}-\ln v_{1}-\ln P\left(\mathrm{H}_{2} \mathrm{O}\right)\right)+E^{\ddagger} .
$$

This suggests that $\beta K_{\mathrm{I}}\left(10^{-5}\right)$ can be determined from $E^{\ddagger}$ for a given environmental condition if $v_{1}$ is assumed constant. Thus, the density of microcracks parallel to the crack propagation direction decreases the activation energy. The effect of the crack density of microcracks on the activation energy can be expressed as follows: 


$$
E^{\ddagger}=E_{0}^{\ddagger}\left(1-\gamma \Phi_{i}\right) \quad(\mathrm{i}=1,2 \text { or } 3)
$$

where $E_{0}^{*}$ is the activation energy of matrix granite material in which no microcracks exist, and $\gamma$ is a constant.

Additionally, from Tables 3-5, the results for Oshima granite and Westerly granite were more reproducible than those for Inadagranite. These results might be due to the different relation between the thickness of the specimen and the mean grain size. The mean grain size of Westerly granite, Oshima granite, and Inada granite were $0.75 \mathrm{~mm} \mathrm{[47],} 1 \mathrm{~mm}$ [48], and $3 \mathrm{~mm} \mathrm{[49],}$ respectively. The reduced thickness of the DT specimen $d_{n}$ (see Fig. 1) was $2 \mathrm{~mm}$. For the specimen of Westerly granite or Oshima granite, $d_{\mathrm{n}}$ was larger than the mean grain size. On the other hand, $d_{n}$ was smaller than the mean grain size for Inada granite. These differences might cause the difference of the reproducibility of the results. 
5.2 Effect of environment on subcritical crack growth

The DT tests for different water vapor pressures demonstrated that subcritical crack growth in granite is facilitated by water vapor in the environment. Kranz [50] noted that the transport of fluids and gases through rocks was reduced and this would have an effect on the corrosion process if a crack closed under confining pressure. However, no confining pressure was applied to the DT specimen in this study. Hence, when the environmental condition was the same, the transport effect of the corrosive agent to the crack tip was the same in this study.

Meredith and Atkinson [51] performed DT tests for water vapor conditions using Westerly granite and Black gabbro, and reported that the crack velocity at a stress intensity factor corresponding to $90 \%$ of the fracture toughness was proportional to $P\left(\mathrm{H}_{2} \mathrm{O}\right)^{1 / 2} \sim P\left(\mathrm{H}_{2} \mathrm{O}\right)$. From Tables 6 and 7 , the dependence of the crack velocity on the water vapor pressure in this study had a similar trend to that observed by Meredith and Atkinson.

To assess the long-term stability of structures in a rock mass, it is necessary to consider the effects of water vapor pressure on crack growth 
behavior. Since subcritical crack growth can be expressed by Eq. (2), it is important to estimate the activation energy $E^{\ddagger}$ and constant $v_{1}$ accurately. For granite, however, the anisotropy of the $K_{\mathrm{I}}-\mathrm{d} a / \mathrm{d} t$ relation due to pre-existing microcracks was demonstrated in Section 4.1. The results indicated that $E^{\ddagger}$ and $v_{1}$ also depended on the crack propagation direction. By assuming that $v_{1}$ was a constant, the effect of the crack density of microcracks on $E^{\ddagger}$ was given by Eq. (15). Substituting Eq. (15) into Eq. (2) yields

$$
\frac{\mathrm{d} a}{\mathrm{~d} t}=v_{1} P\left(\mathrm{H}_{2} \mathrm{O}\right) \exp \left(\frac{-E_{0}^{\ddagger}\left(1-\gamma \Phi_{i}\right)+\beta K_{\mathrm{I}}}{R T}\right) .
$$

Assuming that $\beta$ is a constant, $E_{0}{ }^{*}$ and $v_{1}$ can be estimated from the values of the stress intensity factor or the crack velocity under different values of $T$ and $P\left(\mathrm{H}_{2} \mathrm{O}\right)$. Thus $E_{0}^{*}, \gamma$ and $v_{1}$ may be determined from the DT tests after setting $\beta=0.091$, which is a mean value from experimental results.

Using the values of $\mathrm{d} a / \mathrm{d} t(1.8)$ as input parameters, $E_{0}{ }^{*}=174[\mathrm{~kJ} / \mathrm{mol}], \gamma=3.03$, and $v_{1}=2.24 * 10^{-10}\left[\mathrm{~m} / \mathrm{s} \cdot \mathrm{Pa}^{-1}\right]$. Using the values of $K_{\mathrm{I}}\left(10^{-5}\right)$ as input parameters, $E_{0}^{\ddagger}=183[\mathrm{~kJ} / \mathrm{mol}], \gamma=3.01$, and $v_{1}=5.93 * 10^{-9}\left[\mathrm{~m} / \mathrm{s} \cdot \mathrm{Pa}^{-1}\right]$. The values of $E_{0}^{\ddagger}, \gamma$, and $v_{1}$ obtained with the two sets of input parameters agree well with each other. Thus, the results obtained for granite in this study can be expressed by Eq. 
(16). The average values of $E_{0}^{\ddagger}$ and $\gamma$ are $179 \mathrm{~kJ} / \mathrm{mol}$ and 3.02 , respectively.

The logarithmic average of $v_{1}$ is $1.15^{*} 10^{-9}\left[\mathrm{~m} / \mathrm{s} \cdot \mathrm{Pa}^{-1}\right]$.

The values of $E^{\ddagger}$ determined from DT tests for soda-lime glass [52],

Kumamoto andesite [4], Westerly granite, and Oshimagranite using the same

testing apparatus as this study are listed in Table 8. The values of $E^{\ddagger}$ for granite were calculated from Eq. (15). From the table, it is clear that the $E^{*}$ values for rocks are greater than those for glass. This difference is due to the different fabrics found in glass and rock. Glass is homogeneous and the cracks propagate in a straight line, but since rock is heterogeneous, the cracks do not propagate in a straight line, causing a larger crack path surface energy per unit length as compared to glass. These facts contribute to the larger activation energy for crack propagation in rock.

In addition, the crack path in granite may be transgranular, that is, running across a grain [53-56]. In granite, the orientation of the mineral grains is random. Hence, the crack does not always propagate parallel to the crystal faces or cleavage planes for which the crack growth resistance is low. This might also contribute to the larger activation energy for subcritical crack growth in rock. 
The activation energy values for granite obtained in this study are greater than those reported by Carter et al. [57] (106 $128 \mathrm{~kJ} / \mathrm{mol})$ and less than those reported by Goetze [58] $(327 \mathrm{~kJ} / \mathrm{mol})$. The activation energies obtained by Goetze and Carter et al. were evaluated indirectly using creep tests, and therefore may differ from those obtained using DT tests. The activation energy values for crack growth obtained in this study are more reliable because they were obtained directly from fracture mechanics tests.

Theoretical values of the crack velocity for granite can be calculated for various temperatures, water vapor pressures, crack densities, and stress intensity factors by substituting values of $E_{0}^{*}$ and $v_{1}$ into Eq. (16). A comparison of the theoretically calculated crack velocities $\mathrm{d} a / \mathrm{d} t(1.8)^{\text {th }}$ and the observed crack velocities $\mathrm{d} a / \mathrm{d} t(1.8)$ is shown in Fig. 12. The theoreticalvalues agree well with the observed values, which confirms the reliability of the crack velocity predictions for granite obtained from DT tests.

Fig. 13 shows distributions of the theoretical crack velocities for various temperatures and levels of humidity. In Fig. 13(a) and (b), the crack velocities at $K_{\mathrm{I}}=1.8\left[\mathrm{MN} / \mathrm{m}^{3 / 2}\right]$ are shown for $\Phi_{i}=0.020$ and $\Phi_{i}=0.025$, respectively. It is possible to predict crack velocities theoretically from these 
figures. However, accurate estimates of the activation energies are very important to predict crack growth behavior.

In this study, Eq. (16) was applied only to granite. If sufficient data describing the dependence of other types of rock material on environmental conditions can be obtained, it would also be possible to use Eq. (16), that is, to consider the effects of pre-existing microcracks on the activation energy values for those types of rock. 


\section{Conclusions}

In this study, subcritical crack growth in granite was investigated experimentally using DT tests. The main conclusions are as follows.

1. The relation between the crackvelocity and the stress intensity factor in granite was anisotropic. The anisotropy of subcritical crack growth velocity in granite depended on the crack opening direction and on the density of the microcracks parallel to the crack propagation direction.

2. Crack growth behavior in granite was facilitated under higher water vapor pressure more than under lower water vapor pressure. Increasing water vapor pressure increased the subcritical crack growth velocity in granite.

3. The activation energy of subcritical crack growth for granite was estimated by considering the effects of the crack density of microcracks. The activation energy for crack propagation in granite was greater than that for glass. Glass is a homogeneous material, and cracks tend to propagate in a straight line, whereas granite is a heterogeneous material and cracks tend to propagate in a zigzag pattern. These facts contribute 
to the larger activation energy for granite.

4. Values of the crack velocity for various temperatures, water vapor pressures, crack densities, and stress intensity factors were calculated using the estimated activation energy. The ability of crack velocity prediction technique was demonstrated. 
Appendix A. Calculation of the anisotropic elastic constants

A.1 Modeling the orthorhombic elasticity of granite

For anisotropic materials, the elastic wave velocity, $V$, can be expressed as $[59]$ :

$$
\operatorname{det}\left(C_{i j k l} n_{l} n_{i}-\rho V^{2} \delta_{j k}\right)=0 \quad(i, j, k, l=1 \sim 3)
$$

where $C_{i j k l}$ is the elastic stiffness of the anisotropic material, $n_{i}$ is a vector indicating the propagation direction of the elastic wave, $\rho$ is the density of the material, and $\delta_{j k}$ is the Kronecker delta, which can be expressed as follows:

$$
\left.\begin{array}{rll}
\delta_{j k} & =1 & (j=k) \\
& =0 & (j \neq k)
\end{array}\right\}
$$

Since an orthorhombic material has nine independent elastic constants, it is necessary to measure the elastic wave velocities propagating and vibrating in more than nine different directions. To determine the orthorhombic elastic constants of granite, Sano et al. [12] measured the P-wave and S-wave velocities propagating and vibrating along the principal axes of the material, as well as the S-wave velocities whose propagation directions were inclined at 
$45^{\circ}$ from the principal axes. This method can be applied to any orthorhombic material because the nine elastic constants are determined independently.

From the measurements of Birch [8, 9], Simmons [60], and Sano et al. [12], it is clear that the anisotropic properties of granite decrease with increasing hydrostatic pressure. Their measurements also indicated that the anisotropic properties of granite under low hydrostatic pressures are mainly dependent on the preferred orientation of the microcracks.

If the orthorhombic elasticity of granite is caused by the shape and orientation of pre-existing microcracks, the shape and preferred orientation of pre-existing microcracks possess plane symmetry with respect to the three orthogonal planes of the principal axes. There are several shapes and patterns of preferred orientation that can satisfy the above condition. In this paper, penny-shaped cracks were assumed. The diameter of each crack was $2 a$ and the aspectratio was $\alpha_{R}$. According to the results of Peacock et al. [61], microcracks are oriented in random directions and the microcracks oriented along two orthogonal directions are mixed, as shown in Fig. A.1. If the aspect ratio is sufficiently small, the effect of the microcracks on the elastic properties of the material can be considered with respect to the crack density 
of the microcracks, $\Phi$, expressed as

$$
\Phi=\sum \frac{a^{3}}{V_{C}}
$$

where $V_{C}$ is the volume of the material and $\Sigma$ indicates the sum total with respect to all microcracks in the material.

The model shown in Fig. A.1 contains three different types of crack densities. The case in which the microcracks are distributed in random directions is labeled "Type 0", and Type 0 crack density is expressed as $\Phi_{0}$. The crack densities for Type 2 and 3 are expressed as $\Phi_{2}^{\prime}$ and $\Phi_{3}^{\prime}$, respectively. If the matrix material of the rock is assumed to be isotropic, the number of independent elastic constants is two. Therefore, if the density of the rock, $\rho$, is known, the orthorhombic elasticity for the above model can be expressed by five parameters: the two components of the elastic constants of the matrix material of the rock and the three types of crack density.

Consider an elastic body that contains a microcrack distribution as shown in Fig. A.1. In the remaining sections of the Appendix A, the method used to calculate the effective elastic constants is described first. The method is then compared to Hudson's theory [62-64]. The effective elastic constants and the crack density values are calculated, and the results are evaluated by 
comparing the estimated elastic wave velocities to observed values.

A.2 Calculating the effective elastic constants

Several methods for calculating the effective elastic constants of materials that possess cracks have been proposed. For example, Hudson's [62-64], Knopoff's [65-68], and Toksöz's [69, 70] theories are based on scattering of the elastic waves, and can be used for materials in which the crack density is dilute. Peacock et al. [61] proposed a method to calculate the anisotropic elastic constants and crack densities of microcracks in rock based on Hudson's theory assuming that the rock crack density is dilute. The self consistent scheme (SCS) [71-73] and new self consistent scheme (NSCS) [38, 39] were proposed as theories that consider the interference effects between microcracks. Recently, a method for estimating the elastic constants for rock was proposed using crack tensors [74], which well represented the anisotropy formed by open microcracks [75].

In this study, the NSCS proposed by Yamamoto [38] was used because it can 
be applied to materials in which the crack density is relatively high.

In the NSCS, the effective elastic constants of a material that has a crack density of $\Phi$ can be calculated from

$$
\left.\begin{array}{l}
C_{i j k l}^{n}=C_{i j k l}^{n-1}+\Delta C^{n}{ }_{i j k l} \\
C_{i j k l}^{*}=C^{N}{ }_{i j k l} \\
(n=1 \sim N)
\end{array}\right\},
$$

where $\Delta C^{n}{ }_{i j k l}$ is the increment of the elastic stiffness when there are microcracks corresponding to a crack density of $\Phi / N$ in a homogeneous elastic body whose elastic stiffness is $C_{i j k l}^{n-1} . \Delta C^{n}{ }_{i j k l}$ is calculated from the increment of the strain energy caused by a single isolated crack in an infinite elastic body.

The method used to calculate the Type 2 or 3 crack density will be described first. If the increment of the elastic constants for either the Type 2 or 3 crack densities can be calculated, the remaining value can be obtained in the same manner. Then, the method for calculating the increment of the elastic stiffness due to the $n$ th-step cracks in Eqs. (A.4) for a Type 3 crack density will be presented. The local coordinate system shown in Fig. A.2 (0-1'2'3') is used for these calculations. In the figure, the center of the crack is assumed to be the origin and the normal of the crack plane is along axis-3'. 
The elastic stiffness of the material for the local coordinate system is expressed as $C_{i^{\prime} j^{\prime} k^{\prime} l^{\prime}}$, which is equal to $C_{i j k l}^{n-1}$ because the local coordinate system is consistent with the global coordinate system.

When a strain, $\varepsilon_{i^{\prime} j^{\prime}}$, is applied to an elastic body that contains the crack shown in Fig. A.2, the increment of the elastic stiffness, $\Delta C_{i^{\prime} j^{\prime} k^{\prime} l^{\prime}}$, and strain energy, $\Delta W_{\mathrm{s}}$, can be expressed by eigen strains, $\mathcal{E}^{*}{ }^{\prime} j^{\prime}$, as follows:

$$
\left.\begin{array}{l}
\Delta C_{i^{\prime} j^{\prime} k^{\prime} l^{\prime}}=\frac{\partial^{2} \Delta W_{s}}{\partial \varepsilon_{i^{\prime} j^{\prime}} \partial \varepsilon_{k^{\prime} l^{\prime}}} \\
\Delta W_{s}=\frac{2}{3} \pi \alpha_{R} \Delta \Phi^{\prime}{ }_{3} C_{i^{\prime} j^{\prime} k^{\prime} l^{\prime}} \varepsilon_{k^{\prime} l^{\prime}} \varepsilon^{*}{ }_{i^{\prime} j^{\prime}} \\
\Delta \Phi_{3}^{\prime}=\frac{\Phi_{3}^{\prime}}{N}
\end{array}\right\}
$$

Here, $\varepsilon^{*}{ }^{\prime} j^{\prime}$ for a penny-shaped crack in an anisotropic elastic body can be expressed as [76]

$$
\begin{aligned}
& C_{i^{\prime} j^{\prime} k^{\prime} l^{\prime}} \varepsilon_{k^{\prime} l^{\prime}}=T_{i^{\prime} j^{\prime} m^{\prime} n^{\prime}} \varepsilon^{*}{ }^{*} m^{\prime} n^{\prime} \\
& T_{i^{\prime} j^{\prime} m^{\prime} n^{\prime}}=C_{i^{\prime} j^{\prime} m^{\prime} n^{\prime}}^{n}-C_{i^{\prime} j^{\prime} k^{\prime} l^{\prime}} S_{k^{\prime} l m^{\prime} n^{\prime}} \\
& S_{i^{\prime} j^{\prime} m^{\prime} n^{\prime}}=\frac{\left(F_{i^{\prime} k^{\prime} j^{\prime} l^{\prime}}+F_{j^{\prime} k^{\prime} I^{\prime} l^{\prime}}\right) C^{n-1} k^{\prime} I^{\prime} m^{\prime} n^{\prime}}{2} \\
& \left.F_{i^{\prime} k^{\prime} j^{\prime} l^{\prime}}=\frac{\alpha}{4 \pi} \int_{S^{2}} \frac{\bar{\xi}_{l^{\prime}} \bar{\xi}_{j^{\prime}}}{\left(\bar{\xi}_{1^{\prime}}{ }^{2}+\bar{\xi}_{2^{\prime}}{ }^{2}+\alpha_{R}{ }^{2} \bar{\xi}_{3^{\prime}}{ }^{2}\right)^{3 / 2}} N_{i^{\prime} k^{\prime}}(\bar{\xi}) D^{-1}(\bar{\xi}) d S(\bar{\xi})\right\} \\
& N_{k^{\prime} m^{\prime}}(\bar{\xi})=\epsilon_{k^{\prime} s^{\prime} t^{\prime}} \in_{m^{\prime} n^{\prime} r^{\prime}} K_{n^{\prime} s^{\prime}}(\bar{\xi}) K_{r^{\prime} t^{\prime}}(\bar{\xi}) \\
& K_{k^{\prime} m^{\prime}}(\bar{\xi})=C_{k^{\prime} l^{\prime} m^{\prime} n^{\prime}}^{n-1} \bar{\xi}_{n^{\prime}} \bar{\xi}_{l^{\prime}} \\
& D(\bar{\xi})=\operatorname{det}\left(K_{k^{\prime} m^{\prime}}(\bar{\xi})\right)
\end{aligned}
$$

where $\bar{\xi}$ is a vector describing a point on a unit spherical surface, expressed as $\bar{\xi}=\left(\bar{\xi}_{1}, \bar{\xi}_{2}, \bar{\xi}_{3}\right)$ where $\bar{\xi}_{1}^{2}+\bar{\xi}_{2}^{2}+\bar{\xi}_{3}^{2}=1, \int_{S^{2}} d S(\bar{\xi})$ indicates integration over a 
unit spherical surface, and $\epsilon_{k s t}$ is the permutation tensor for which $\epsilon_{123}=\epsilon_{231}=\epsilon_{312}=1, \epsilon_{132}=\epsilon_{321}=\epsilon_{213}=-1$, and $\epsilon_{k s t}=0$ for all other cases. Therefore, $\Delta C^{n}{ }_{i j k l}$ can be evaluated if the increment of the elastic stiffness in Eqs. (A.5) is transformed to the global coordinate system. Similar calculations are possible for the Type 2 crack density. In these cases, the suffix of the elastic stiffness must be transformed according to

$$
\text { Tyре } 2: 1 \rightarrow 2,2 \rightarrow 3,3 \rightarrow 1
$$

and $\Phi_{3}^{\prime}$ in Eq. (A.5) must be replaced by $\Phi_{2}^{\prime}$. Consequently, for the model shown in Fig. A.1, the increment of the elastic stiffness with respect to the cracks distributed in each direction is calculated in each calculation step, and the sum of each increment is assumed to be the total increment of the elastic stiffness for that calculation step.

The calculation procedure for the Type 0 crack density is different from that of the Type 2 or 3 crack densities. Since the cracks are oriented randomly, the probability of the existence of cracks in all directions is constant, and the expectation value of the increment of the elastic stiffness due to these cracks can be calculated. For a crack oriented in any direction, if the local coordinate system is defined as Fig. A.2, the elastic stiffness, $C_{i^{\prime} j^{\prime} k^{\prime} l^{\prime}}$, can be 
expressed as

$$
\left.\begin{array}{l}
C_{i^{\prime} j^{\prime} k^{\prime} l^{\prime}}=d_{i i^{\prime}} d_{j j^{\prime}} d_{k k^{\prime}} d_{l l^{\prime}} C^{n-1}{ }_{i j k l} \\
d_{i j^{\prime}}=\left(\begin{array}{ccc}
\sin \theta & -\cos \theta & 0 \\
\sin \varphi \cos \theta & \sin \varphi \sin \theta & -\cos \varphi \\
\cos \varphi \cos \theta & \cos \varphi \sin \theta & \sin \varphi
\end{array}\right)
\end{array}\right\}
$$

where $d_{i j^{\prime}}$ is the directional cosine. $\Delta C_{i^{\prime} j^{\prime} k^{\prime} l^{\prime}}$ can be obtained by substituting the result from Eq. (A.7) into Eqs. (A.5) and (A.6). The increment of the elastic stiffness, $\Delta C^{n}{ }_{i j k l}$, can be estimated from the following integration:

$$
\Delta C_{i j k l}^{n}=\frac{\pi}{2} \int_{0}^{2 \pi} \int_{0}^{\pi / 2} d_{i i^{\prime}} d_{j j} d_{k k^{\prime}} d_{l l^{\prime}} \Delta C_{i^{\prime} j^{\prime} k^{\prime} l^{\prime}} \cos \varphi d \varphi d \theta \quad \text { (A.8) }
$$

Consequently, the increment of the elastic constants for each crack group, Types 0,2 , and 3 , is calculated in each calculation step, and the sum of the values is assumed to be the total increment of the elastic constants.

A. 3 Comparison with Hudson's theory

The theory of Hudson [62-64] for randomly oriented cracks was used to verify the calculation method used in this study. Hudson's theory can be expressed as

$$
C_{i j k l}=C_{i j k l}^{0}+C_{i j k l}^{1 \mathrm{st}}+C_{i j k l}^{2 \mathrm{nd}} \quad(i, j, k, l=1,2 \text { or } 3)
$$


where $C_{i j k l}$ is the effective elastic constant of cracked rock, $C_{i j k l}^{0}$ is the elastic constant of uncracked rock, $C_{i j k l}^{1 s t}$ is the first-order perturbations of the elastic constants, that is, the perturbations due to individual microcracks, and $C_{i j k l}^{2 n d}$ is the second-order perturbations due to interaction of the microcracks. $C_{i j k l}^{0}$ can be expressed as

$$
C_{i j k l}^{0}=\lambda \delta_{i j} \delta_{k l}+\mu\left(\delta_{i k} \delta_{j l}+\delta_{i l} \delta_{j k}\right) \quad(\mathrm{A} .10)
$$

where $\lambda$ and $\mu$ are the Lame constants for uncracked rock and $\delta_{i j}$ is the Kronecker delta.

Fig. A.3 shows the relation between the elastic constants and the crack density of the microcracks. In this figure, the solid lines indicate the results obtained from the NSCS, the broken lines indicate the results obtained from Hudson's solution including only first-order terms, and the dotted lines indicate the results obtained from Hudson's solution including first- and second-order terms. The values of the elastic constants agree well when the crack density is less than 0.05. With increasing crack density, the difference between the values becomes larger. The values obtained by the NSCS are larger than those obtained from Hudson's solution including only first-order terms, and smaller than those obtained from Hudson's solution including 
first- and second-order terms.

A.4 Calculation of the effective elastic constants and the crack densities

If the elastic moduli of the rock matrix material and the values of the crack

density in the direction of the principal axes are known, the effective elastic constants of the orthorhombic material can be calculated. The elastic wave velocities are determined by substituting the effective elastic constants into Eq. (A.1). If a backward analysis of the elastic constants is performed to reduce the error between the theoretical and observed values of the elastic wave velocities as much as possible, the determined effective elastic constants can be assumed to be the actual elastic constants of the rock. The error of the elastic wave velocities, $e$, is given as

$$
e=\frac{1}{M} \sum\left|\frac{V^{\text {th }}-V^{\mathrm{ob}}}{V^{\mathrm{th}}}\right| \times 100 \quad[\%]
$$

where $M$ is the number of velocity values used in the analysis, and $V^{\text {th }}$ and $V^{\text {ob }}$ are the theoretical and observed values of the velocity, respectively. In this study, the error of the three components of the P-wave velocities for the 
three principal axes was defined as $e_{\mathrm{p}}$, the error of the six components of the S-wave velocities propagating and vibrating parallel to the principal axes was defined as $e_{\mathrm{s}}$, and the error of the nine components of the elastic wave velocities propagating and vibrating parallel to the principal axes, $e_{a}$, was defined as

$$
e_{\mathrm{a}}=\frac{e_{\mathrm{P}}+e_{\mathrm{S}}}{2} \quad[\%] \quad(\mathrm{A} .12) .
$$

Since it is difficult to use the least squares algorithm to minimize wave velocity errors in a backward analysis, the elastic constants are calculated within some assumed crack density values and the effective elastic constants are determined when the error of the wave velocities is minimized. Although a very large number of calculations will be necessary, the number can be decreased if the number of parameters and the range of the initially assumed values of the crack density are limited.

The elastic properties of the rock matrix materials are determined from the composition of the rock-forming minerals [70]. Granite contains approximately $30 \%$ quartz, plagioclase, and potash feldspar, and several percent biotite. The constitutional ratio of the rock-forming minerals in granite does not vary much from quarry to quarry, and the elastic constants 
of the granite matrix material remain relatively constant. This can be confirmed from reported measurements of the elastic wave velocities [8, 9] or the linear compressibility [78] of granite. Young's modulus and Poisson's ratio of the granite matrix material determined from the elastic wave velocity values of several types of granite under high hydrostatic pressures (100 MPa) are $79.2 \pm 3.5 \mathrm{GPa}$ and $0.245 \pm 0.01$, respectively. Assuming that these represent the truevalues for granite, Young's modulus and Poisson's ratio for the granite matrix were fixed to $80 \mathrm{GPa}$ and 0.25 , respectively, in this study. The three crack density components were then estimated.

The calculations were performed with an aspect ratio $\alpha_{\mathrm{R}}=10^{-3}$ and number of iterative calculations $N=100$ since there is little effect on the results when $\alpha_{\mathrm{R}} \leq 10^{-3}$ and $N \geq 100[79]$

A.5 Evaluation of the effective elastic constants and the crack density

The elastic wave velocities measured in Oshima granite and Inada granite are listed in Table A.1. In the table, $V_{i i}$ is the $\mathrm{P}-$ wave velocity and $V_{i j}$ is the 
S-wave velocity propagating parallel to axis- $i$ and vibrating parallel to axis- $j$ $(i, j=1,2,3)$. The elastic wave propagation in granite was anisotropic and the relation $V_{i j} \approx V_{j i}$ held for the S-wave velocity. Therefore, granite can be considered an orthorhombic material.

The theoretically calculated values of the crack densities, elastic constants, and elastic wave velocities are shown in Table A.2 for minimum values of $e_{a}$. Mean density values of the Oshima granite and Inada granite specimens were 2670 and $2640 \mathrm{~kg} / \mathrm{m}^{3}$, respectively. Comparing Tables A. 1 and A.2, the values of the elastic wave velocity agree within a $6 \%$ error. Hence, the evaluated elastic constants can be considered to be reliable.

The relation between the elastic constants when $e_{\mathrm{a}}$ is minimized, $C_{I J}{ }^{(\mathrm{PS})}$, and the elastic constants when $e_{\mathrm{P}}$ is minimized, $C_{I J}{ }^{(\mathrm{P})}$, is shown in Fig. A.4. The $C_{I J}{ }^{(\mathrm{P})}$ values agree well with the $C_{I J}{ }^{(\mathrm{PS})}$ values. Therefore, the elastic constants for granite can be estimated from the P-wave velocities along the three principal axes. 
Appendix B. Data about subcritical crack growth index

The values of subcritical crack growth index $n_{s}$ have been determined and discussed by many researchers for rocks [80]. The values of $n_{\mathrm{s}}$ determined for Westerly granite, Oshima granite, an Inada granite using Eq. (4) [23] are listed in Tables A.3, A.4, and A.5, respectively. From these tables, it is shown that $n_{\mathrm{s}}$ tend to be smaller when the crack growth occurred parallel to plane-3 if the environmental condition was the same. Additionally, from Tables A.3 and A.4, it is shown that $n_{\text {s }}$ tend to be smaller when the water vapor pressure is higher. Therefore, it is considered that $n_{s}$ for granite may be dependent on the crack propagation direction and water vapor pressure.

The values of $n_{\mathrm{s}}$ agreed with those in air conditions by Atkinson and Rawlings [81] $\left(n_{\mathrm{s}} \approx 40\right)$ for Westerly granite and a little larger than those by Sano and Kudo [17] for Oshima granite $\left(n_{\mathrm{s}} \approx 31\right)$ when the crack growth occurred parallel to plane-3 and the water vapor pressure was high. On the other hand, when the crack propagated parallel to plane-1 or plane-2, or when the water vapor pressure was low, the values of $n_{s}$ agreed with those by Swanson [44] $\left(n_{\mathrm{s}} \approx 70\right)$. 


\section{References}

[1] Atkinson BK, Meredith PG. The theory of subcritical crack growth with applications to minerals and rocks. In: Atkinson BK, editor. Fracture mechanics of rock. London: Academic Press; 1987. p. 111-66.

[2] Anderson OL, Grew PC. Stress corrosion theory of crack propagation with applications to geophysics. Rev Geophys Space Phys 1977;15:77-104.

[3] Dove PM. Geochemical controls on the kinetics of quartz fracture at subcritical tensile stresses. J Geophys Res 1995;100:22349-59.

[4] Nara Y, and Kaneko K. Study of subcritical crackgrowth in andesite using double torsion test. Int J Rock Mech Min Sci 2005;42:521-30.

[5] Obara Y, Sakaguchi K, Nakayama T, Sugawara K. Anisotropy effect on fracture toughness of rock. Proceedings of the EUROCK'92, 1992.p. 7-12.

[6] Douglass PM, Voight B. Anisotropy of granites: a reflection of microscopic fabric. Geotechnique 1969;19:376-98.

[7] Peng S, Johnson AM. Crack growth and faulting in cylindrical specimens of Chelmsford granite. Int J Rock Mech Min Sci 1972;9:37-86.

[8] Birch F. The velocity of compressional waves in rocks to 10 Kilobars, Part 
1. J Geophys Res 1960;65:1083-102.

[9] Birch F. The velocity of compressional waves in rocks to 10 Kilobars, Part 2. J Geophys Res 1961;66:2199-224.

[10]Thill RE, Bur TR, Steckley RC. Velocity anisotropy in dry and saturated rock spheres and its relation to rock fabric. Int. J Rock Mech Min Sci Geomech Abstr 1973;10:535-57.

[11]Kudo Y, Hashimoto K, Sano O, Nakagawa K. Relation between physical anisotropy and microstructures of granitic rock in Japan. In: Herget G, Vongpaisal S, editors. Proceedings of the sixth international congress on rock mechanics. Montreal. Rotterdam: A.A. Balkema;1987.p.429-32.

[12] Sano O, Kudo Y, Mizuta Y. Experimental determination of elastic constants of Oshima granite, Barre granite and Chelmsford granite. J Geophys Res 1992;97(B3):3367-79.

[13] Scholz CH. Static fatigue of quartz. J Geophys Res 1972;77:2104-14.

[14]Atkinson BK. A fracture mechanics study of subcritical tensile cracking of quartz in wet environments. PAGEOPH 1979;117:1011-24.

[15]Atkinson BK. Subcritical crack growth in geological materials. J Geophys Res 1984;89:4077-4114. 
[16] Henry JP, Paquet J, Tancrez JP. Experimental study of crack propagation in calcite rocks. Int J Rock Mech Min Sci Geomech Abstr 1977;14:85-91.

[17] Sano O, Kudo Y. Relation of fracture resistance to fabric for granitic rocks, PAGEOPH 1992;138(4):657-77.

[18] Michalske TA, Freiman SW. A molecular interpretation of stress corrosion in silica. Nature 1982;295:511-2.

[19]Wiederhorn SM. Influence of water vapor on crack propagation in soda-lime glass. J Am Ceram Soc 1967;50:407-14.

[20] Soga N, Okamoto T, Hanada T, Kunugi M. Chemical reaction between water vapor and stressed glass. J Am Ceram Soc 1979;62:309-10.

[21] Wiederhorn SM, Fuller Jr ER, Thomson R. Micromechanisms of crack growth in ceramics and glasses in corrosive environments. Met Sci $1980 ; 14: 450-8$.

[22] Baumgartner A, Enders G, Kirchner M, Mayer H. Global climatology. In: Plate E, editor. Engineering Meteorology, 1982.p. 125-77.

[23] Charles RJ. Static fatigue of glass, II. J Appl Phys 1959;29:1554-60.

[24]Kies JA, Clark ABJ. Fracture propagation rates and times to fail following proof stress in bulk glass. In: Platt PL editor. Fracture. London: 
Chapman and Hall; 1969. p. 483-91.

[25]Evans AG. A method for evaluating the time-dependent failure characteristics of brittle materials and its applications to polycrystalline alumina. J Mater Sci 1972;7:1137-46.

[26]Williams DP, Evans AG. A simple method for studying slow crack growth.

J Test Eval 1973;1:264-70.

[27] Evans AG, Linzer M, Russel LR. Acoustic emission and crack propagation in polycrystalline alumina. Mater Sci Eng 1974;15:253-61.

[28]Atkinson BK. Fracture toughness of Tennessee sandstone and Carrara marble using the double torsion testing method. Int J Rock Mech Min Sci Geomech Abstr 1979;16:46-53.

[29]Pletka BJ, Fuller Jr ER, Koepke BG. An evaluation of double-torsion testing - Experimental. ASTM STP 678; 1979. p. 19-37.

[30]Trantina GG. Stress analysis of the double-torsion specimen. J Am Ceram Soc $1977 ; 60: 338-41$.

[31]Ciccoti M. Realistic finite-element method for double-torsion loading configuration. J Am Ceram Soc 2000;83:2737-44.

[32]Ciccotti M, Gonzato G, Mulargia F. The double torsion loading 
configuration for fracture propagation: an improved methodology for the load-relaxation at constant displacement. Int $J$ Rock Mech Min Sci $2000 ; 37: 1103-13$.

[33] Ciccotti M, Negri N, Sassi L, Gonzato G, Mulargia F. Elastic and fracture parameters of Etna, Stromboli, and Vulcano lava rocks, J Volcanol Geother Res 2000;98:209-17.

[34]Ciccotti M, Negri N, Gonzato G, Mulargia F. Practical application of an improved methodology for the double torsion load relaxation method, Int J Rock Mech Min Sci 2001;38:569-76.

[35]Dale TN. The commercial granite of New England. Bull US Geol Surv $1923 ; 738: 22-103$.

[36]Peng SS, Johnson AM. Crack growth and faulting in cylindrical specimens of Chelmsford granite. Int J Rock Mech Min Sci 1972;9:37-86.

[37]Kato M, Yoneda T, Kaneko K. Three-dimensional distribution of microcrack orientation and its quantitative relation to anisotropy of permeability of granite. Proceedings of the second international workshop on the application of geophysics to rock engineering, Paris, 1999. p. $42-7$. 
[38] Yamamoto K. Theoretical determination of effective elastic constants of composite and its application to seismology. PhD thesis, Tohoku University, 1981.

[39] Yamamoto K, Kosuga K, Hirasawa T. A theoretical method for determination of effective elastic constants of isotropic composite. Sci Rep Tohoku Univ Ser 5 (Tohoku Geophys J) 1981;28:47-67.

[40]Ingraffea AR, Gunsallus KL, Beech JF, Nelson PP. A short-rod based system for fracture toughness testing of rock. ASTM STP 855; 1984.p. $152-66$.

[41]Hashimoto K, Kudo Y, Yatomi C, Nakagawa K. Crack propagation and anisotropy of fracture toughness in granite. Proceedings of $21 \mathrm{st}$ symposium of rock mechanics, Tokyo, 1989.p.446-50 (in Japanese).

[42]Utagawa M, Seto M, Katsuyama K, Katsui K. The evaluation of fracture toughness of rock in wet and chemical conditions. Proceedings of the '99 Japan-Korea joint symposium on rock engineering, Fukuoka, 1999. p. $573-8$.

[43] Lin W, Takahashi M, Kwasniewski M, Hirono T. Experimental evaluation of anisotropy of physical and mechanical properties of a granite. 
Proceedings of the EUROCK 2004 and 53rd geomechanics colloquium, Salzburg, 2004 .p. 503-6.

[44]Swanson PL. Subcritical crack growth and other time- and environment-dependent behavior in crustal rocks. J Geophys Res $1984 ; 89: 4137-52$.

[45]Nara Y, Yoneda T, Kaneko K. Anisotropy of subcritical crack growth in granite. Proceedings of the third Korea-Japan joint symposium on rock engineering, vol. 1.2002.p. 235-42.

[46] Nara Y, Yoneda T, Kaneko K. Analysis of crack path for subcritical crack growth in rocks. Proceedings of the EUROCK 2005, 2005.p.405-12.

[47]Sprunt ES, Brace WF. Direct observation of microcavities in crystalline rocks. Int J Rock Mech Min Sci Geomech Abstr 1974;11:139-50.

[48]Sano O. A note on the sources of acoustic emissions associated with subcritical crack growth. Int J Rock Mech Min Sci Geomech Abstr $1981 ; 18: 259-63$.

[49]Lin W, Ohta Y, Takahashi M, Sugita N. Effect of strain rate on compressive strength and deformability of granite. Shigen-to-Sozai 2002;118:377-84 (in Japanese with English abstract). 
[50]Kranz RL. The effect of confining pressure and stress difference on static fatigue of granite. J Geophys Res 1980;85:1854-66.

[51] Meredith PG, Atkinson BK. Fracture toughness and subcritical crack growth during high-temperature tensile deformation of Westerly granite and Black gabbro. Phys Earth Planet Int 1985;39:33-51.

[52]Nara Y, Kurata H, Kaneko K. Effects of rock fabrics and environmental conditions on subcritical crack growth in rocks. Proceedings of 40 th US rock mechanics symposium, Paper ID.736,2005 (in attached CD-ROM).

[53]Kranz RL. Microcracks in rocks: a review. Tectonophysics $1983 ; 100: 449-80$.

[54]Swanson PL. Subcritical fracture propagation in rocks: an examination using the methods of fracture mechanics and non-destructive testing. PhD thesis, University of Colorado, 1985.

[55]Kudo Y, Sano O, Murashige N, Mizuta Y. Stress-induced crack path in Aji granite under tensile stress, PAGEOPH 1992;138:641-56.

[56]Nara Y. Study of subcritical crack growth in granite. Masters thesis, Hokkaido University, 2001 (in Japanese).

[57] Carter NL, Anderson DA, Hansen FD, Kranz RL. Creep and creep rupture 
of granitic rocks. In: Carter NL, Friedman M, Logan JM, Stearns DW, editors. Mechanical behavior of crustal rocks. Washington, DC: American Geophysical Union; 1981.p. 61-82.

[58]Goetze C. High temperature rheology of Westerly granite. J Geophys Res $1971 ; 76: 1223-30$.

[59]Love AEH. A treatise on the mathematical theory of elasticity. New York: Dover Publications; 1944.

[60]Simmons G. Velocity of shear waves in rocks to 10 kilobars. J Geophys Res $1964 ; 69(6): 1123-30$.

[61]Peacock S, McCann C, Sothcott J, Astin TR. Seismic velocities in fractured rocks: an experimental verification of Hudson's theory. Geophys Prospect 1994;42:27-80.

[62]Hudson JA. Overall properties of a cracked solid. Math Proc Cambridge Phil Soc 1980;88:371-84.

[63] Hudson JA. Wave speeds and attenuation of elastic waves in material containing cracks. Geophys J R Astr Soc 1981;64:133-50.

[64]Hudson JA. A higher order approximation to the wave propagation constants for a cracked solid. Geophys J R Astr Soc 1986;87:265-74. 
[65]Mal AK, Knopoff L. Elastic wave velocities in two-component systems. J Inst Math Appl 1967;3:376-87.

[66] Garbin HD, Knopoff L. The compressional modulus of a material permeated by a random distribution of circular cracks. Q Appl Math $1973 ; 30: 453-64$.

[67]Garbin HD, Knopoff L. The shear modulus of a material permeated by a random distribution of free circular cracks. Q Appl Math $1975 ; 33: 296-300$.

[68]Garbin HD, Knopoff L. Elastic moduli of a medium with liquid-filled cracks. Q Appl Math 1975;33:301-3.

[69]Kuster GT, Toksöz MN. Velocity and attenuation of seismic waves in two-phase media: Part 1. Theoretical formulations. Geophysics $1974 ; 39: 587-606$.

[70]Toksöz MN, Cheng CH, Timur A. Velocities of seismic waves in porous rocks. Geophysics 1976;41:621-45.

[71]Hill R. A self-consistent mechanics of composite materials. J Mech Phys Solids 1965;13:213-22.

[72] O'Connell RJ, Budiansky B. Seismic velocities in dry and saturated 
cracked solids. J Geophys Res 1974;79:5412-26.

[73] Budiansky B, O’Connell RJ. Elastic moduli of a cracked solid. Int J Solid Struct $1976 ; 12: 81-97$.

[74] Oda M. Fabric tensor for discontinuous geological materials. Soils Found $1982 ; 22: 96-108$.

[75] Takemura T, Golshani A, Oda M, Suzuki K. Preferred orientations of open microcracks in granite and their relation with anisotropic elasticity. Int J Rock Mech Min Sci 2003;40:443-54.

[76]Mura T, Mori S. Micromechanics. Baifukan, 1976 (in Japanese).

[77]Brace WF. Relation between elastic properties of rocks to fabric. J Geophys Res 1965;70:5657-67.

[78]Brace WF. Some new measurements of linear compressibility of rocks. J Geophys Res 1965;70:391-8.

[79]Tanaka Y, Verdeja E, Kaneko K. A method to evaluate the three dimensional deformability of jointed rock based on EVDM. Shigen-to-Sozai 1994;110:1165-74 (in Japanese with English abstract).

[80]Atkinson BK, Meredith PG. Experimental fracture mechanics data for rocks and minerals. In: Atkinson BK, editor. Fracture mechanics of rock. 
London: Academic Press; 1987.p. 477-525.

[81]Atkinson BK, Rawlings RD. Acoustic emission during stress corrosion cracking in rocks. In: Simpson DW, Richards P, editors. Earthquake prediction. Washington, DC: American Geophysical Union; 1981. p. $605-16$. 
Table 1 The P-wave velocities for granite.

\begin{tabular}{|c|c|c|c|}
\hline \multirow{2}{*}{ Rocks } & \multicolumn{3}{|c|}{ P-wave velocity [km/s] } \\
\cline { 2 - 4 } & axis-1 & axis-2 & axis-3 \\
\hline \hline Westerly granite & 4.83 & 4.80 & 4.72 \\
\hline Oshima granite & 4.91 & 4.61 & 4.51 \\
\hline Inada granite & 4.69 & 4.33 & 4.06 \\
\hline
\end{tabular}

Table 2 The crack densities and the elastic constants for granites.

\begin{tabular}{|c|c|c|c|c|c|c|c|}
\hline Rocks & Crack density & \multicolumn{6}{|c|}{ Effective compliance $\left[\times 10^{-12} \mathrm{~Pa}^{-1}\right]$} \\
\hline \multirow{6}{*}{ Westerly granite } & \multirow{6}{*}{$\begin{array}{l}\Phi_{0}=0.200 \\
\Phi_{2}^{\prime}=0.002 \\
\Phi_{3}{ }_{3}=0.009\end{array}$} & 17.4 & -3.30 & -3.30 & 0 & 0 & 0 \\
\hline & & -3.30 & 17.6 & -3.30 & 0 & 0 & 0 \\
\hline & & -3.30 & -3.30 & 18.1 & 0 & 0 & 0 \\
\hline & & 0 & 0 & 0 & 42.5 & 0 & 0 \\
\hline & & 0 & 0 & 0 & 0 & 42.3 & 0 \\
\hline & & 0 & 0 & 0 & 0 & 0 & 41.6 \\
\hline \multirow{6}{*}{ Oshima granite } & \multirow{6}{*}{$\begin{array}{l}\Phi_{0}=0.176 \\
\Phi_{2}^{\prime}=0.026 \\
\Phi_{3}{ }_{3}=0.036\end{array}$} & 16.7 & -3.28 & -3.28 & 0 & 0 & 0 \\
\hline & & -3.28 & 18.9 & -3.28 & 0 & 0 & 0 \\
\hline & & -3.28 & -3.28 & 19.7 & 0 & 0 & 0 \\
\hline & & 0 & 0 & 0 & 46.0 & 0 & 0 \\
\hline & & 0 & 0 & 0 & 0 & 43.4 & 0 \\
\hline & & 0 & 0 & 0 & 0 & 0 & 42.4 \\
\hline \multirow{6}{*}{ Inada granite } & \multirow{6}{*}{$\begin{array}{l}\Phi_{0}=0.224 \\
\Phi_{2}^{\prime}=0.031 \\
\Phi_{3}^{\prime}=0.060\end{array}$} & 18.1 & -3.32 & -3.32 & 0 & 0 & 0 \\
\hline & & -3.32 & 21.1 & -3.32 & 0 & 0 & 0 \\
\hline & & -3.32 & -3.32 & 23.9 & 0 & 0 & 0 \\
\hline & & 0 & 0 & 0 & 52.9 & 0 & 0 \\
\hline & & 0 & 0 & 0 & 0 & 49.1 & 0 \\
\hline & & 0 & 0 & 0 & 0 & 0 & 46.1 \\
\hline
\end{tabular}

$\Phi_{0}:$ The crack density of random oriented microcracks

$\Phi_{2}^{\prime}$ and $\Phi_{3}^{\prime}$ : The crack density of oriented microcracks perpendicular to axis-2 2 and axis-3, respectively 
Table 3 Results of DT test for Westerly granite for condition-A.

Water vapor pressure was $570 \mathrm{~Pa}$. SD means the standard deviation.

\begin{tabular}{|c|c|c|c|c|c|}
\hline crack opening direction & specimen & $\alpha$ & $\beta\left[\mathrm{m}^{5 / 2} / \mathrm{mol}\right]$ & $\begin{array}{c}K_{I}\left(10^{-5}\right) \\
{\left[\mathrm{MN} / \mathrm{m}^{3 / 2}\right]}\end{array}$ & da/dt (1.8) [m/s] \\
\hline \hline axis-1 & $2 \cdot 1$ & $-81.6 \pm 9.5$ & $0.084 \pm 0.011$ & $1.97 \pm 0.05$ & $\begin{array}{c}2.45 * 10^{-8} \\
\left(\mathrm{SD} \text { is } 0.45 \times 10^{1} \mathrm{in} \mathrm{log}\right)\end{array}$ \\
\hline axis-2 & $1 \cdot 2$ & $-88.2 \pm 1.0$ & $0.093 \pm 0.001$ & $1.96 \pm 0.02$ & $\begin{array}{c}1.82 * 10^{-8} \\
\left(\mathrm{SD} \text { is } 0.22 \times 10^{1} \mathrm{in} \mathrm{log}\right)\end{array}$ \\
\hline axis-3 & $1 \cdot 3$ & $-82.2 \pm 12.2$ & $0.091 \pm 0.014$ & $1.85 \pm 0.05$ & $\begin{array}{c}1.29 * 10^{-6} \\
\left(\mathrm{SD} \text { is } 0.74 \times 10^{1} \mathrm{in} \mathrm{log}\right)\end{array}$ \\
\hline
\end{tabular}

Table 4 Results of DT test for Oshima granite for condition-A.

Water vapor pressure was $570 \mathrm{~Pa}$. SD means the standard deviation.

\begin{tabular}{|c|c|c|c|c|c|}
\hline crack opening direction & specimen & $\alpha$ & $\beta\left[\mathrm{m}^{5 / 2} / \mathrm{mol}\right]$ & $\begin{array}{c}K_{I}\left(10^{-5}\right) \\
{\left[\mathrm{MN} / \mathrm{m}^{3 / 2}\right]} \\
\end{array}$ & $d a / d t(1.8)[\mathrm{m} / \mathrm{s}]$ \\
\hline \multirow{2}{*}{ axis-1 } & $2 \cdot 1$ & $-81.9 \pm 21.0$ & $0.084 \pm 0.030$ & $2.00 \pm 0.13$ & $\begin{array}{c}1.66 * 10^{-8} \\
\left(\mathrm{SD} \text { is } 1.02 \times 10^{1} \text { in log) }\right.\end{array}$ \\
\hline & $3 \cdot 1$ & $-95.2 \pm 15.8$ & $0.100 \pm 0.021$ & $1.97 \pm 0.07$ & $\begin{array}{c}6.16^{*} * 10^{-9} \\
\left(\mathrm{SD} \text { is } 1.48 \times 10^{1} \text { in log) }\right.\end{array}$ \\
\hline \multirow{2}{*}{ axis-2 } & $1 \cdot 2$ & $-93.5 \pm 15.4$ & $0.107 \pm 0.024$ & $1.82 \pm 0.08$ & $\begin{array}{c}6.76^{*} 10^{-6} \\
\left(\mathrm{SD} \text { is } 2.45 \times 10^{1} \mathrm{in} \log \right)\end{array}$ \\
\hline & $3 \cdot 2$ & $-87.5 \pm 10.5$ & $0.098 \pm 0.012$ & $1.82 \pm 0.04$ & $\begin{array}{c}3.72 * 10^{-6 \pm 0.77} \\
\left(\mathrm{SD} \text { is } 0.59 \times 10^{1} \text { in log) }\right.\end{array}$ \\
\hline \multirow{2}{*}{ axis-3 } & $1 \cdot 3$ & $-99.7 \pm 24.3$ & $0.120 \pm 0.031$ & $1.74 \pm 0.04$ & $\begin{array}{c}1.96 * 10^{-4} \\
\left(\mathrm{SD} \text { is } 0.47 \times 10^{1} \mathrm{in} \log \right)\end{array}$ \\
\hline & $2 \cdot 3$ & $-81.7 \pm 13.6$ & $0.097 \pm 0.019$ & $1.72 \pm 0.08$ & $\begin{array}{c}3.31 * 10^{-4} \\
\left(\mathrm{SD} \text { is } 3.47 \times 10^{1} \text { in log) }\right.\end{array}$ \\
\hline
\end{tabular}


Table 5 Results of DT test for Inada granite for condition-A.

Water vapor pressure was $570 \mathrm{~Pa}$. SD means the standard deviation.

\begin{tabular}{|c|c|c|c|c|c|}
\hline crack opening direction & specimen & $\alpha$ & $\beta\left[\mathrm{m}^{5 / 2} / \mathrm{mol}\right]$ & $\begin{array}{c}K_{I}\left(10^{-5}\right) \\
{\left[\mathrm{MN} / \mathrm{m}^{3 / 2}\right]}\end{array}$ & $d a / d t(1.4)[\mathrm{m} / \mathrm{s}]$ \\
\hline \multirow{2}{*}{ axis-1 } & $2 \cdot 1$ & $-85.5 \pm 12.3$ & $0.111 \pm 0.016$ & $1.59 \pm 0.10$ & $\begin{array}{c}1.31 * 10^{-9} \\
\left(\mathrm{SD} \text { is } 1.38 \times 10^{2} \text { in log) }\right.\end{array}$ \\
\hline & $3 \cdot 1$ & $-84.1 \pm 7.1$ & $0.115 \pm 0.015$ & $1.52 \pm 0.08$ & $\begin{array}{c}3.23 * 10^{-8} \\
\left(\mathrm{SD} \text { is } 5.62 \times 10^{1} \text { in log) }\right.\end{array}$ \\
\hline \multirow{2}{*}{ axis-2 } & $1 \cdot 2$ & $-78.8 \pm 14.3$ & $0.117 \pm 0.022$ & $1.38 \pm 0.07$ & $\begin{array}{c}1.92 * 10^{-5} \\
\left(\mathrm{SD} \text { is } 3.24 \times 10^{1} \text { in } \log \right)\end{array}$ \\
\hline & $3 \cdot 2$ & $-81.3 \pm 17.3$ & $0.126 \pm 0.032$ & $1.35 \pm 0.11$ & $\begin{array}{c}1.85 * 10^{-4} \\
\left(\mathrm{SD} \text { is } 7.08 \times 10^{2} \text { in log) }\right.\end{array}$ \\
\hline \multirow{2}{*}{ axis-3 } & $1 \cdot 3$ & $-69.4 \pm 11.8$ & $0.107 \pm 0.020$ & $1.23 \pm 0.09$ & $\begin{array}{c}1.84 * 10^{-2} \\
\left(\mathrm{SD} \text { is } 5.13 \times 10^{1} \text { in log) }\right.\end{array}$ \\
\hline & $2 \cdot 3$ & $-64.7 \pm 12.4$ & $0.109 \pm 0.018$ & $1.17 \pm 0.14$ & $\begin{array}{c}2.83 * 10^{-1} \\
\left(\mathrm{SD} \text { is } 1.41 \times 10^{2} \text { in log) }\right.\end{array}$ \\
\hline
\end{tabular}

Table 6 Results of DT test for Westerly granite for condition-A and -B.

SD means the standard deviation.

\begin{tabular}{|c|c|c|c|c|c|c|}
\hline specimen & & condition & $\alpha$ & $\beta\left[\mathrm{m}^{5 / 2} / \mathrm{mol}\right]$ & $\begin{array}{c}K_{\mathrm{I}}\left(10^{-5}\right) \\
{\left[\mathrm{MN} / \mathrm{m}^{3 / 2}\right]}\end{array}$ & $\begin{array}{c}d a / d t(1.8) \\
{[\mathrm{m} / \mathrm{s}]}\end{array}$ \\
\hline \multirow{2}{*}{$2 \cdot 1$} & $\mathrm{~A}$ & $\begin{array}{c}284.1 \mathrm{~K}, 44 \% \\
\mathrm{P}\left(\mathrm{H}_{2} \mathrm{O}\right)=570 \mathrm{~Pa}\end{array}$ & $-81.6 \pm 9.5$ & $0.084 \pm 0.011$ & $1.97 \pm 0.05$ & $\begin{array}{c}2.45^{*} 10^{-8} \\
\left(\mathrm{SD} \text { is } 0.45 \times 10^{1} \mathrm{in} \log \right)\end{array}$ \\
\hline & $\mathrm{B}$ & $\begin{array}{c}329.7 \mathrm{~K}, 73 \% \\
\mathrm{P}\left(\mathrm{H}_{2} \mathrm{O}\right)=12.3 \mathrm{kPa}\end{array}$ & $-73.6 \pm 6.5$ & $0.093 \pm 0.011$ & $1.83 \pm 0.05$ & $\begin{array}{c}3.98^{*} 10^{-6} \\
\left(\mathrm{SD} \text { is } 0.66 \times 10^{1} \text { in } \log \right)\end{array}$ \\
\hline \multirow{2}{*}{$1 \cdot 2$} & $\mathrm{~A}$ & $\begin{array}{c}284.1 \mathrm{~K}, 44 \% \\
\mathrm{P}\left(\mathrm{H}_{2} \mathrm{O}\right)=570 \mathrm{~Pa}\end{array}$ & $-88.2 \pm 1.0$ & $0.093 \pm 0.001$ & $1.96 \pm 0.02$ & $\begin{array}{c}1.82 * 10^{-8} \\
\left(\mathrm{SD} \text { is } 0.22 \times 10^{1} \mathrm{in} \log \right)\end{array}$ \\
\hline & $\mathrm{B}$ & $\begin{array}{c}329.7 \mathrm{~K}, 73 \% \\
\mathrm{P}\left(\mathrm{H}_{2} \mathrm{O}\right)=12.3 \mathrm{kPa}\end{array}$ & $-63.9 \pm 7.1$ & $0.076 \pm 0.010$ & $1.88 \pm 0.08$ & $\begin{array}{c}1.10^{*} 10^{-6} \\
\left(\mathrm{SD} \text { is } 1.20 \times 10^{1} \mathrm{in} \log \right)\end{array}$ \\
\hline \multirow{2}{*}{$1 \cdot 3$} & $\mathrm{~A}$ & $\begin{array}{c}284.1 \mathrm{~K}, 44 \% \\
\mathrm{P}\left(\mathrm{H}_{2} \mathrm{O}\right)=570 \mathrm{~Pa}\end{array}$ & $-82.7 \pm 12.2$ & $0.091 \pm 0.014$ & $1.85 \pm 0.05$ & $\begin{array}{c}1.29 * 10^{-6} \\
\left(\mathrm{SD} \text { is } 0.74 \times 10^{1} \mathrm{in} \log \right)\end{array}$ \\
\hline & B & $\begin{array}{c}329.7 \mathrm{~K}, 73 \% \\
\mathrm{P}\left(\mathrm{H}_{2} \mathrm{O}\right)=12.3 \mathrm{kPa}\end{array}$ & $-58.5 \pm 7.6$ & $0.073 \pm 0.013$ & $1.77 \pm 0.07$ & $\begin{array}{c}2.75^{*} 10^{-5} \\
\left(\mathrm{SD} \text { is } 0.85 \times 10^{1} \mathrm{in} \log \right)\end{array}$ \\
\hline
\end{tabular}


Table 7 Results of DT test for Oshima granite for condition-A and -B.

SD means the standard deviation.

\begin{tabular}{|c|c|c|c|c|c|c|}
\hline specimen & & condition & $\alpha$ & $\beta\left[\mathrm{m}^{5 / 2} / \mathrm{mol}\right]$ & $\begin{array}{c}K_{\mathrm{I}}\left(10^{-5}\right) \\
{\left[\mathrm{MN} / \mathrm{m}^{3 / 2}\right]}\end{array}$ & $\begin{array}{c}d a / d t(1.8) \\
\quad[\mathrm{m} / \mathrm{s}]\end{array}$ \\
\hline \multirow{2}{*}{$2 \cdot 1$} & $\mathrm{~A}$ & $\begin{array}{c}284.1 \mathrm{~K}, 44 \% \\
\mathrm{P}\left(\mathrm{H}_{2} \mathrm{O}\right)=570 \mathrm{~Pa}\end{array}$ & $-81.9 \pm 21.0$ & $0.084 \pm 0.030$ & $2.00 \pm 0.13$ & $\begin{array}{c}1.66^{*} 10^{-8} \\
\left(\mathrm{SD} \text { is } 1.02 \times 10^{1} \mathrm{in} \log \right)\end{array}$ \\
\hline & B & $\begin{array}{c}329.7 \mathrm{~K}, 73 \% \\
\mathrm{P}\left(\mathrm{H}_{2} \mathrm{O}\right)=12.3 \mathrm{kPa}\end{array}$ & $-82.2 \pm 6.5$ & $0.104 \pm 0.012$ & $1.87 \pm 0.06$ & $\begin{array}{c}8.32 * 10^{-7} \\
\left(\mathrm{SD} \text { is } 0.55 \times 10^{1} \mathrm{in} \log \right)\end{array}$ \\
\hline \multirow{2}{*}{$3 \cdot 1$} & A & $\begin{array}{c}284.1 \mathrm{~K}, 44 \% \\
\mathrm{P}\left(\mathrm{H}_{2} \mathrm{O}\right)=570 \mathrm{~Pa}\end{array}$ & $-95.2 \pm 15.8$ & $0.100 \pm 0.021$ & $1.97 \pm 0.07$ & $\begin{array}{c}6.16^{*} 10^{-9} \\
\left(\mathrm{SD} \text { is } 1.48 \times 10^{1} \mathrm{in} \log \right)\end{array}$ \\
\hline & B & $\begin{array}{c}329.7 \mathrm{~K}, 73 \% \\
\mathrm{P}\left(\mathrm{H}_{2} \mathrm{O}\right)=12.3 \mathrm{kPa}\end{array}$ & $-72.2 \pm 2.1$ & $0.088 \pm 0.003$ & $1.89 \pm 0.02$ & $\begin{array}{c}6.31 * 10^{-7} \\
\left(\mathrm{SD} \text { is } 0.19 \times 10^{1} \mathrm{in} \log \right)\end{array}$ \\
\hline \multirow{2}{*}{$1 \cdot 2$} & A & $\begin{array}{c}284.1 \mathrm{~K}, 44 \% \\
\mathrm{P}\left(\mathrm{H}_{2} \mathrm{O}\right)=570 \mathrm{~Pa}\end{array}$ & $-93.5 \pm 15.4$ & $0.107 \pm 0.024$ & $1.82 \pm 0.08$ & $\begin{array}{c}6.76^{*} 10^{-6} \\
\left(\mathrm{SD} \text { is } 2.45 \times 10^{1} \mathrm{in} \log \right)\end{array}$ \\
\hline & B & $\begin{array}{c}329.7 \mathrm{~K}, 73 \% \\
\mathrm{P}\left(\mathrm{H}_{2} \mathrm{O}\right)=12.3 \mathrm{kPa}\end{array}$ & $-72.0 \pm 19.3$ & $0.092=$ & $1.80 \pm 0.13$ & $\begin{array}{c}7.08 * 10^{-6} \\
\left(\mathrm{SD} \text { is } 5.62 \times 10^{1} \mathrm{in} \log \right)\end{array}$ \\
\hline \multirow{2}{*}{$3 \cdot 2$} & A & $\begin{array}{c}284.1 \mathrm{~K}, 44 \% \\
\mathrm{P}\left(\mathrm{H}_{2} \mathrm{O}\right)=570 \mathrm{~Pa}\end{array}$ & $-87.5 \pm 10.5$ & $0.098 \pm 0.012$ & $1.82 \pm 0.04$ & $\begin{array}{c}3.72 * 10^{-6} \\
\left(\mathrm{SD} \text { is } 0.59 \times 10^{1} \mathrm{in} \log \right)\end{array}$ \\
\hline & B & $\begin{array}{c}329.7 \mathrm{~K}, 73 \% \\
\mathrm{P}\left(\mathrm{H}_{2} \mathrm{O}\right)=12.3 \mathrm{kPa}\end{array}$ & $-50.7 \pm 3.9$ & $0.063 \pm 0.008$ & $1.70 \pm 0.04$ & $\begin{array}{c}1.12 * 10^{-4} \\
\left(\mathrm{SD} \text { is } 0.32 \times 10^{1} \mathrm{in} \log \right)\end{array}$ \\
\hline \multirow{2}{*}{$1 \cdot 3$} & A & $\begin{array}{c}284.1 \mathrm{~K}, 44 \% \\
\mathrm{P}\left(\mathrm{H}_{2} \mathrm{O}\right)=570 \mathrm{~Pa}\end{array}$ & $-99.7 \pm 24.3$ & $0.120 \pm 0.031$ & $1.74 \pm 0.04$ & $\begin{array}{c}1.96 * 10^{-4} \\
\left(\mathrm{SD} \text { is } 0.47 \times 10^{1} \mathrm{in} \log \right)\end{array}$ \\
\hline & B & $\begin{array}{c}329.7 \mathrm{~K}, 73 \% \\
\mathrm{P}\left(\mathrm{H}_{2} \mathrm{O}\right)=12.3 \mathrm{kPa}\end{array}$ & $-72.4 \pm 7.1$ & $0.098 \pm 0.015$ & $1.71 \pm 0.09$ & $\begin{array}{c}3.72 * 10^{-4} \\
\left(\mathrm{SD} \text { is } 4.27 \times 10^{1} \mathrm{in} \log \right)\end{array}$ \\
\hline \multirow{2}{*}{3} & A & $\begin{array}{c}284.1 \mathrm{~K}, 44 \% \\
\mathrm{P}\left(\mathrm{H}_{2} \mathrm{O}\right)=570 \mathrm{~Pa}\end{array}$ & $-81.7 \pm 13.6$ & $0.097 \pm 0.019$ & $1.72 \pm 0.08$ & $\begin{array}{c}3.31^{*} 10^{-4} \\
\left(\mathrm{SD} \text { is } 3.47 \times 10^{1} \mathrm{in} \log \right)\end{array}$ \\
\hline & B & $\begin{array}{c}329.7 \mathrm{~K}, 73 \% \\
\mathrm{P}\left(\mathrm{H}_{2} \mathrm{O}\right)=12.3 \mathrm{kPa}\end{array}$ & $-60.8 \pm 11.5$ & $0.081 \pm 0.017$ & $1.67 \pm 0.10$ & $\begin{array}{c}3.98 * 10^{-4} \\
\left(\mathrm{SD} \text { is } 1.55 \times 10^{1} \mathrm{in} \log \right)\end{array}$ \\
\hline
\end{tabular}

Table 8 The summary of the activation energy for glass [52], andesite [4] and granite.

\begin{tabular}{|l|c|}
\hline \multicolumn{1}{|c|}{ materials } & $\begin{array}{c}\text { Activation energy } \\
{[\mathrm{kJ} / \mathrm{mol}]}\end{array}$ \\
\hline \hline soda-lime glass & 50 \\
\hline Kumamoto andesite & 124 \\
\hline Westerly granite (parallel to plane-1) & 172 \\
\hline Westerly granite (parallel to plane-2) & 171 \\
\hline Westerly granite (parallel to plane-3) & 167 \\
\hline Oshima granite (parallel to plane-1) & 173 \\
\hline Oshima granite (parallel to plane-2) & 159 \\
\hline Oshima granite (parallel to plane-3) & 154 \\
\hline
\end{tabular}


Table A.1 Measured values of the elastic wave velocity.

\begin{tabular}{|c|c|c|c|c|c|c|c|c|c|}
\hline \multirow{2}{*}{ Rocks } & \multicolumn{10}{|c|}{ Elastic wave velocity [km/s] } \\
\cline { 2 - 11 } & $\mathrm{V}_{11}$ & $\mathrm{~V}_{22}$ & $\mathrm{~V}_{33}$ & $\mathrm{~V}_{12}$ & $\mathrm{~V}_{21}$ & $\mathrm{~V}_{23}$ & $\mathrm{~V}_{32}$ & $\mathrm{~V}_{13}$ & $\mathrm{~V}_{31}$ \\
\hline \hline Oshima & 4.91 & 4.61 & 4.51 & 2.97 & 2.91 & 2.81 & 2.82 & 2.82 & 2.81 \\
\hline Inada & 4.69 & 4.33 & 4.06 & 2.75 & 2.78 & 2.54 & 2.51 & 2.61 & 2.59 \\
\hline
\end{tabular}

Table A.2 The crack densities, the elastic constants and the wave velocities for the granites.

\begin{tabular}{|c|c|c|c|c|c|c|c|c|c|}
\hline Rocks & Crack density & \multicolumn{6}{|c|}{ Effective compliance $\left[\times 10^{-12} \mathrm{~Pa}^{-1}\right]$} & \multicolumn{2}{|c|}{ Theoretical wave velocity $[\mathrm{km} / \mathrm{s}]$} \\
\hline \multirow{5}{*}{ Oshima granite } & & 16.7 & -3.28 & -3.28 & $\overline{0}$ & 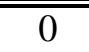 & 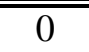 & \multirow{5}{*}{$\begin{array}{ll}\mathrm{V}_{11}=4.92 & \mathrm{~V}_{12}=2.93 \\
\mathrm{~V}_{22}=4.62 & \mathrm{~V}_{21}=2.93 \\
\mathrm{~V}_{33}=4.51 & \mathrm{~V}_{31}=2.90\end{array}$} & \multirow{5}{*}{$\begin{array}{l}V_{13}=2.90 \\
V_{23}=2.81 \\
V_{32}=2.81\end{array}$} \\
\hline & $\Phi_{0}=0.176$ & -3.28 & 18.9 & -3.28 & 0 & 0 & 0 & & \\
\hline & $\Phi_{2}^{\prime}=0.026$ & -3.28 & -3.28 & 19.7 & 0 & 0 & 0 & & \\
\hline & $\Phi_{3}^{\prime}=0.036$ & 0 & 0 & $\begin{array}{l}0 \\
0\end{array}$ & $\begin{array}{c}46.0 \\
0\end{array}$ & $\begin{array}{c}0 \\
434\end{array}$ & 0 & & \\
\hline & & 0 & 0 & 0 & 0 & 0 & 42.4 & & \\
\hline \multirow{6}{*}{ Inada granite } & & 18.1 & -3.32 & -3.32 & 0 & 0 & 0 & \multirow{6}{*}{$\begin{array}{ll}V_{11}=4.92 & V_{12}=2.93 \\
V_{22}=4.62 & V_{21}=2.93 \\
V_{33}=4.51 & V_{31}=2.90\end{array}$} & \multirow{6}{*}{$\begin{array}{l}V_{13}=2.90 \\
V_{23}=2.81 \\
V_{32}=2.81\end{array}$} \\
\hline & $\Phi_{0}=0.224$ & -3.32 & 21.1 & -3.32 & 0 & 0 & 0 & & \\
\hline & $\Phi_{2}^{\prime}=0.031$ & -3.32 & -3.32 & 23.9 & 0 & 0 & 0 & & \\
\hline & $\Phi^{\prime}{ }_{3}=0.060$ & 0 & 0 & 0 & 52.9 & 0 & 0 & & \\
\hline & & 0 & 0 & 0 & 0 & 49.1 & 0 & & \\
\hline & & 0 & 0 & 0 & 0 & 0 & 46.1 & & \\
\hline
\end{tabular}

$\Phi_{0}:$ The crack density of random oriented microcracks

$\Phi_{2}^{\prime}$ and $\Phi_{3}^{\prime}$ : The crack density of oriented microcracks

perpendicular to axis-2 and axis-3, respectively

Table A.3 Subcritical crack growth index $n_{\mathrm{s}}$ for Westerly granite.

\begin{tabular}{|c|c|c|c|}
\hline \multirow{2}{*}{$2 \cdot 1$} & \multicolumn{2}{|c|}{ condition } & subcritical crack growth index \\
\hline \hline \multirow{2}{*}{$1 \cdot 2$} & A & $\begin{array}{c}284.1 \mathrm{~K}, 44 \% \\
\mathrm{P}\left(\mathrm{H}_{2} \mathrm{O}\right)=570 \mathrm{~Pa}\end{array}$ & $69.3 \pm 9.5$ \\
\cline { 2 - 4 } & B & $\begin{array}{c}329.7 \mathrm{~K}, 73 \% \\
\mathrm{P}\left(\mathrm{H}_{2} \mathrm{O}\right)=12.3 \mathrm{kPa}\end{array}$ & $62.1 \pm 7.9$ \\
\hline \multirow{2}{*}{$1 \cdot 3$} & A & $\begin{array}{c}284.1 \mathrm{~K}, 44 \% \\
\mathrm{P}\left(\mathrm{H}_{2} \mathrm{O}\right)=570 \mathrm{~Pa}\end{array}$ & $77.0 \pm 0.7$ \\
\cline { 2 - 4 } & B & $\begin{array}{c}329.7 \mathrm{~K}, 73 \% \\
\mathrm{P}\left(\mathrm{H}_{2} \mathrm{O}\right)=12.3 \mathrm{kPa}\end{array}$ & $52.3 \pm 8.6$ \\
\hline \multirow{2}{*}{$\begin{array}{c}\text { A } \\
284.1 \mathrm{~K}, 44 \% \\
\mathrm{P}\left(\mathrm{H}_{2} \mathrm{O}\right)=570 \mathrm{~Pa}\end{array}$} & $\begin{array}{c}329.7 \mathrm{~K}, 73 \% \\
\mathrm{P}\left(\mathrm{H}_{2} \mathrm{O}\right)=12.3 \mathrm{kPa}\end{array}$ & $70.9 \pm 12.1$ \\
\hline
\end{tabular}


Table A.4 Subcritical crack growth index $n_{\mathrm{s}}$ for Oshima granite.

\begin{tabular}{|c|c|c|c|}
\hline specimen & & condition & subcritical crack grwoth index \\
\hline \multirow{2}{*}{$2 \cdot 1$} & $\mathrm{~A}$ & $\begin{array}{c}284.1 \mathrm{~K}, 44 \% \\
\mathrm{P}\left(\mathrm{H}_{2} \mathrm{O}\right)=570 \mathrm{~Pa}\end{array}$ & $70.2 \pm 21.2$ \\
\hline & B & $\begin{array}{c}329.7 \mathrm{~K}, 73 \% \\
\mathrm{P}\left(\mathrm{H}_{2} \mathrm{O}\right)=12.3 \mathrm{kPa}\end{array}$ & $70.3 \pm 6.4$ \\
\hline \multirow{2}{*}{$3 \cdot 1$} & A & $\begin{array}{c}284.1 \mathrm{~K}, 44 \% \\
\mathrm{P}\left(\mathrm{H}_{2} \mathrm{O}\right)=570 \mathrm{~Pa}\end{array}$ & $83.2 \pm 15.7$ \\
\hline & B & $\begin{array}{c}329.7 \mathrm{~K}, 73 \% \\
\mathrm{P}\left(\mathrm{H}_{2} \mathrm{O}\right)=12.3 \mathrm{kPa}\end{array}$ & $60.5 \pm 2.2$ \\
\hline \multirow{2}{*}{$1 \cdot 2$} & $\mathrm{~A}$ & $\begin{array}{c}284.1 \mathrm{~K}, 44 \% \\
\mathrm{P}\left(\mathrm{H}_{2} \mathrm{O}\right)=570 \mathrm{~Pa}\end{array}$ & $82.2 \pm 15.6$ \\
\hline & B & $\begin{array}{c}329.7 \mathrm{~K}, 73 \% \\
\mathrm{P}\left(\mathrm{H}_{2} \mathrm{O}\right)=12.3 \mathrm{kPa}\end{array}$ & $60.3 \pm 19.3$ \\
\hline \multirow{2}{*}{$3 \cdot 2$} & $\mathrm{~A}$ & $\begin{array}{c}284.1 \mathrm{~K}, 44 \% \\
\mathrm{P}\left(\mathrm{H}_{2} \mathrm{O}\right)=570 \mathrm{~Pa}\end{array}$ & $76.0 \pm 10.4$ \\
\hline & B & $\begin{array}{c}329.7 \mathrm{~K}, 73 \% \\
\mathrm{P}\left(\mathrm{H}_{2} \mathrm{O}\right)=12.3 \mathrm{kPa}\end{array}$ & $70.3 \pm 6.4$ \\
\hline \multirow{2}{*}{$1 \cdot 3$} & $\mathrm{~A}$ & $\begin{array}{c}284.1 \mathrm{~K}, 44 \% \\
\mathrm{P}\left(\mathrm{H}_{2} \mathrm{O}\right)=570 \mathrm{~Pa}\end{array}$ & $87.6 \pm 24.0$ \\
\hline & B & $\begin{array}{c}329.7 \mathrm{~K}, 73 \% \\
\mathrm{P}\left(\mathrm{H}_{2} \mathrm{O}\right)=12.3 \mathrm{kPa}\end{array}$ & $60.8 \pm 7.1$ \\
\hline \multirow{2}{*}{$2 \cdot 3$} & $\mathrm{~A}$ & $\begin{array}{c}284.1 \mathrm{~K}, 44 \% \\
\mathrm{P}\left(\mathrm{H}_{2} \mathrm{O}\right)=570 \mathrm{~Pa}\end{array}$ & $70.5 \pm 13.4$ \\
\hline & B & $\begin{array}{c}329.7 \mathrm{~K}, 73 \% \\
\mathrm{P}\left(\mathrm{H}_{2} \mathrm{O}\right)=12.3 \mathrm{kPa}\end{array}$ & $49.2 \pm 11.5$ \\
\hline
\end{tabular}


Table A.5 Subcritical crack growth index $n_{\mathrm{s}}$ for Inada granite.

\begin{tabular}{|c|c|c|c|}
\hline specimen & \multicolumn{2}{|c|}{ condition } & subcritical crack grwoth index \\
\hline \hline $2 \cdot 1$ & A & $\begin{array}{c}284.1 \mathrm{~K}, 44 \% \\
\mathrm{P}\left(\mathrm{H}_{2} \mathrm{O}\right)=570 \mathrm{~Pa}\end{array}$ & $73.9 \pm 12.3$ \\
\hline $3 \cdot 1$ & $\mathrm{~A}$ & $\begin{array}{c}284.1 \mathrm{~K}, 44 \% \\
\mathrm{P}\left(\mathrm{H}_{2} \mathrm{O}\right)=570 \mathrm{~Pa}\end{array}$ & $75.1 \pm 9.4$ \\
\hline $1 \cdot 2$ & $\mathrm{~A}$ & $\begin{array}{c}284.1 \mathrm{~K}, 44 \% \\
\mathrm{P}\left(\mathrm{H}_{2} \mathrm{O}\right)=570 \mathrm{~Pa}\end{array}$ & $67.2 \pm 14.3$ \\
\hline $3 \cdot 2$ & $\mathrm{~A}$ & $\begin{array}{c}284.1 \mathrm{~K}, 44 \% \\
\mathrm{P}\left(\mathrm{H}_{2} \mathrm{O}\right)=570 \mathrm{~Pa}\end{array}$ & $69.8 \pm 17.0$ \\
\hline $1 \cdot 3$ & $\mathrm{~A}$ & $\begin{array}{c}284.1 \mathrm{~K}, 44 \% \\
\mathrm{P}\left(\mathrm{H}_{2} \mathrm{O}\right)=570 \mathrm{~Pa}\end{array}$ & $54.9 \pm 11.7$ \\
\hline $2 \cdot 3$ & A & $\begin{array}{c}284.1 \mathrm{~K}, 44 \% \\
\mathrm{P}\left(\mathrm{H}_{2} \mathrm{O}\right)=570 \mathrm{~Pa}\end{array}$ & $53.1 \pm 12.4$ \\
\hline
\end{tabular}




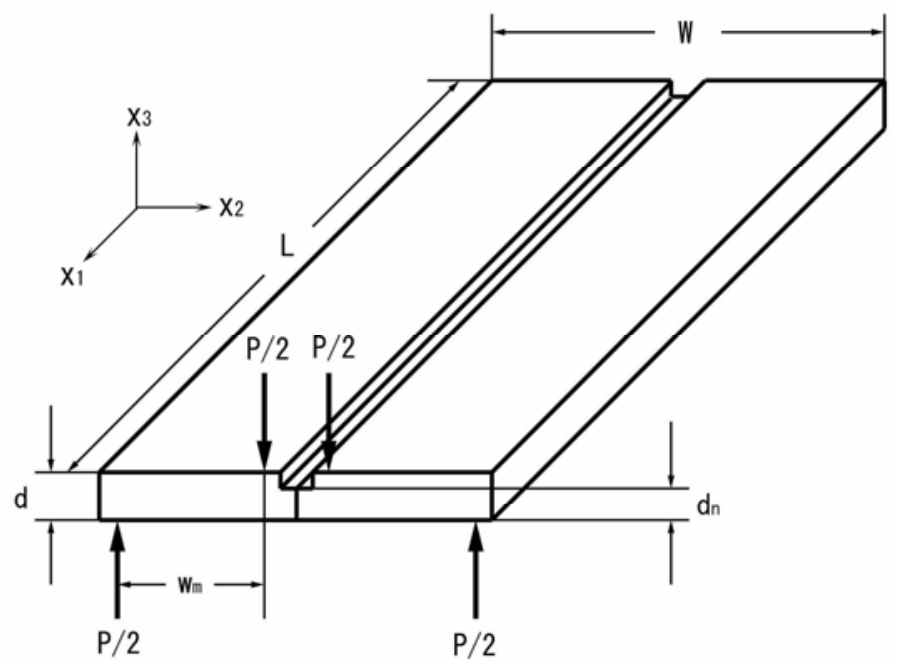

Fig. 1 An illustration of the DT specimen.

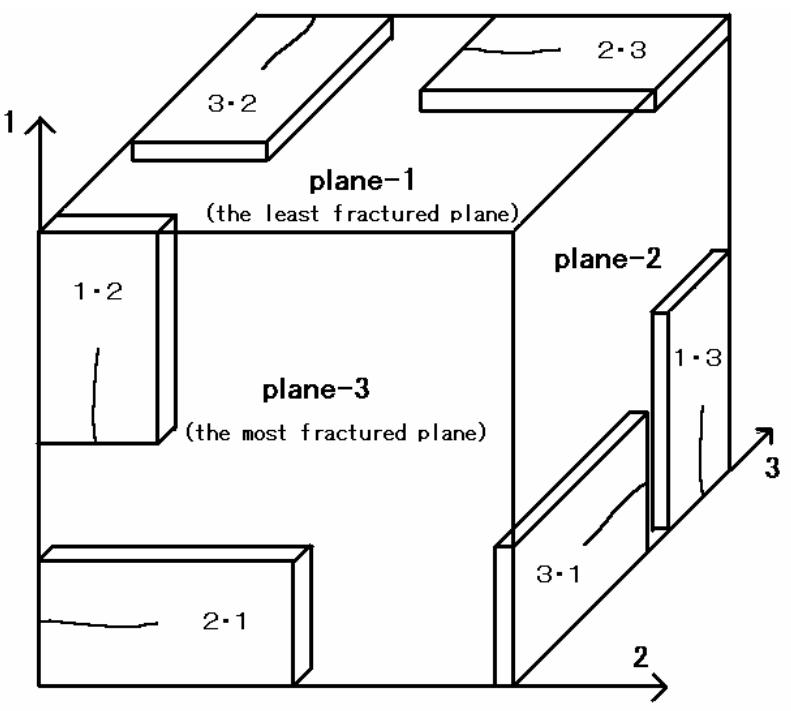

Fig. 2 A schematic view of the specimen orientations. Plane- 1 is the least fractured plane and plane-3 is the most fractured plane.

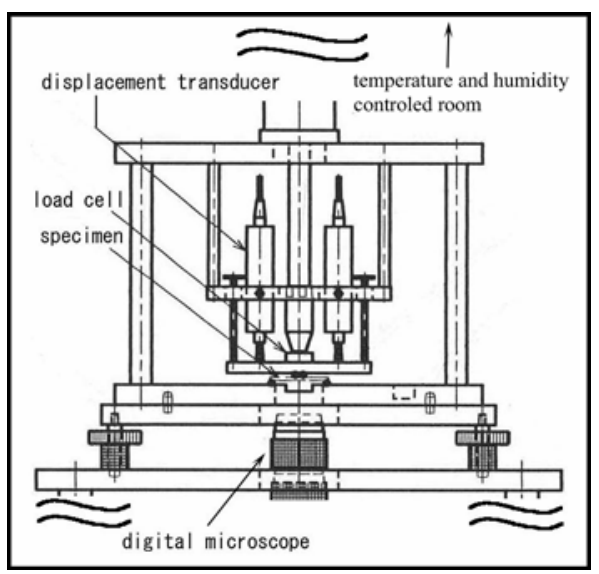

Fig. 3 A schematic illustration of the DT testing apparatus .apparatus. 


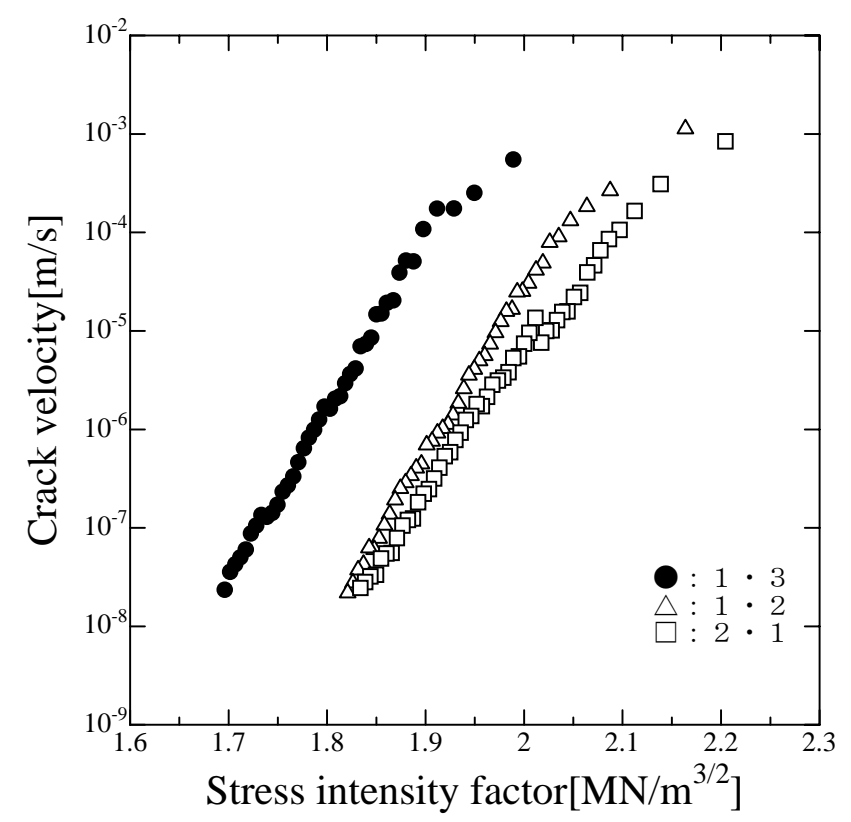

Fig. 4 Relation between the stress intensity factor and the crack velocity for Westerly granite.

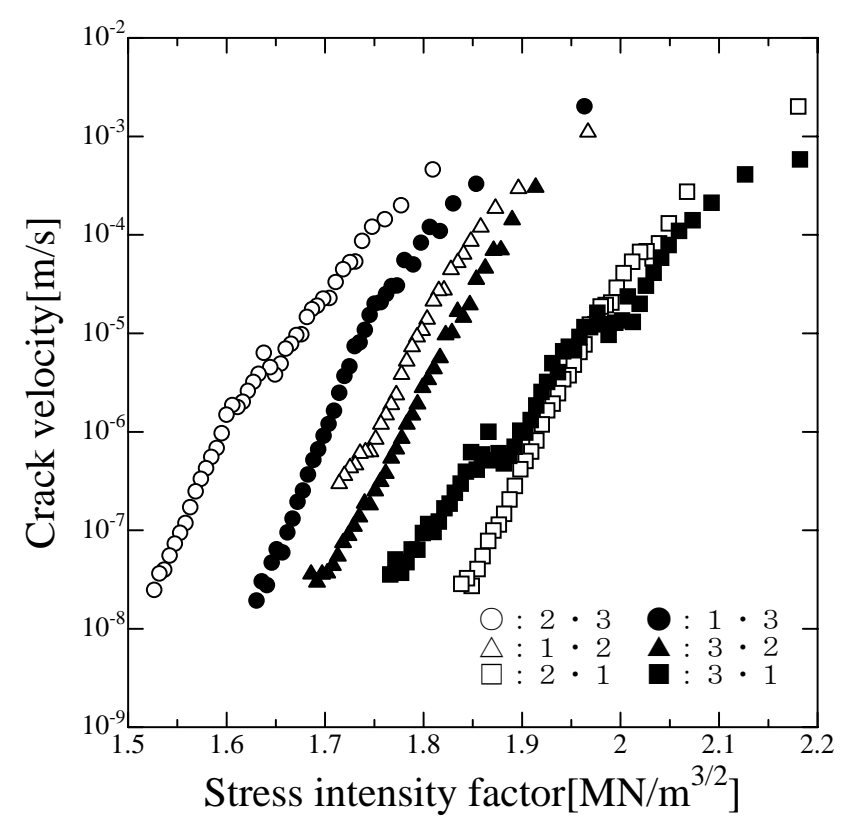

Fig. 5 Relation between the stress intensity factor and the crack velocity for Oshima granite. 


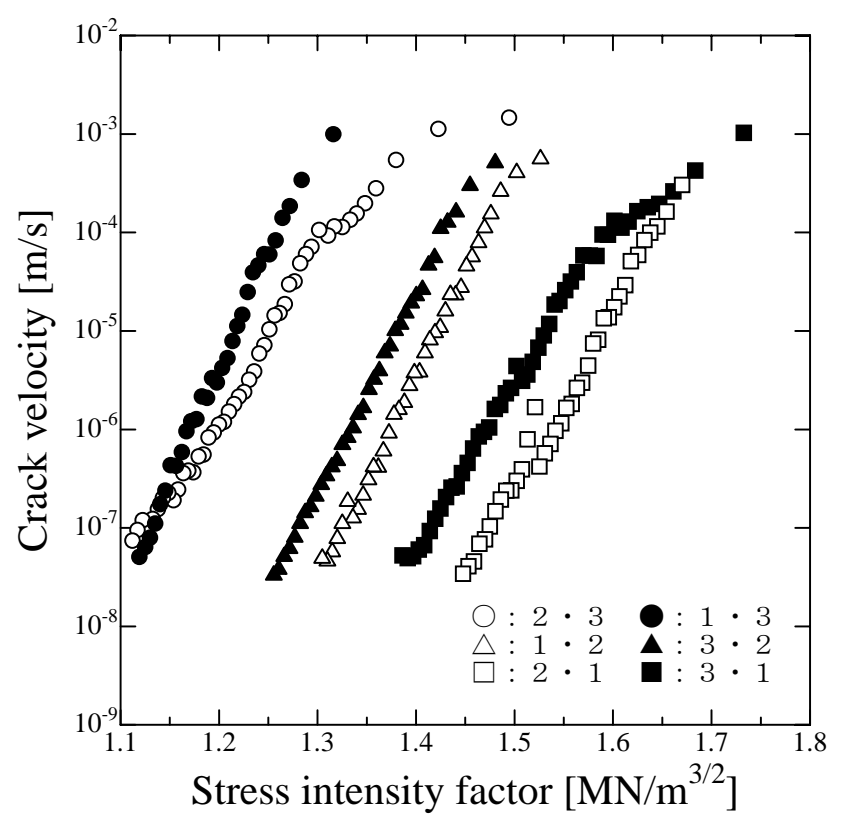

Fig. 6 Relation between the stress intensity factor and the crack velocity for Inada granite.

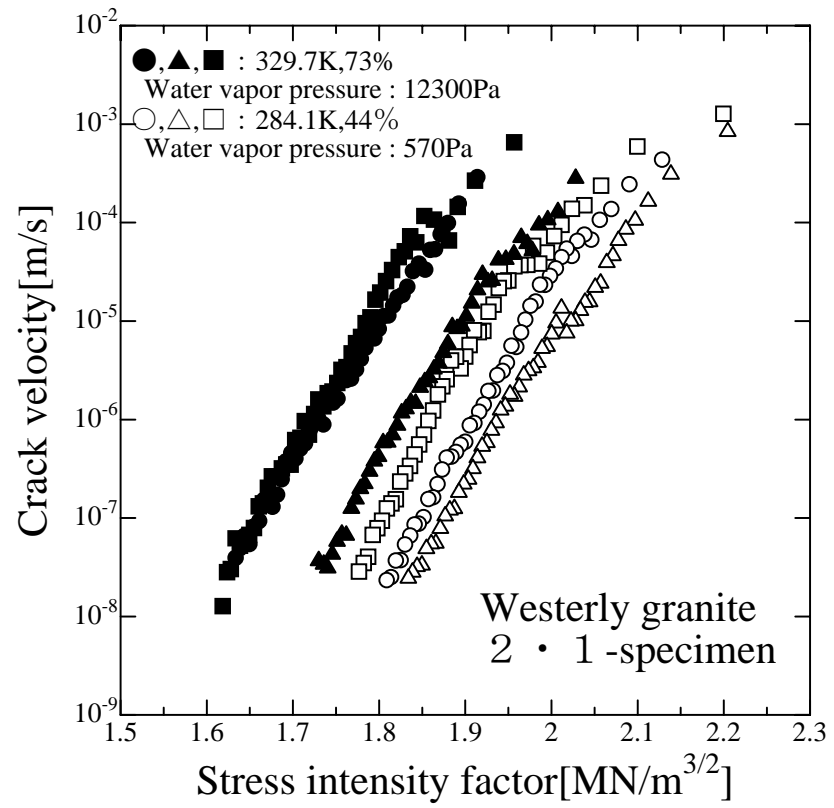

Fig. 7 Relation between the stress intensity factor and the crack velocity for Westerly granite ( 2 - 1 -specimen). 


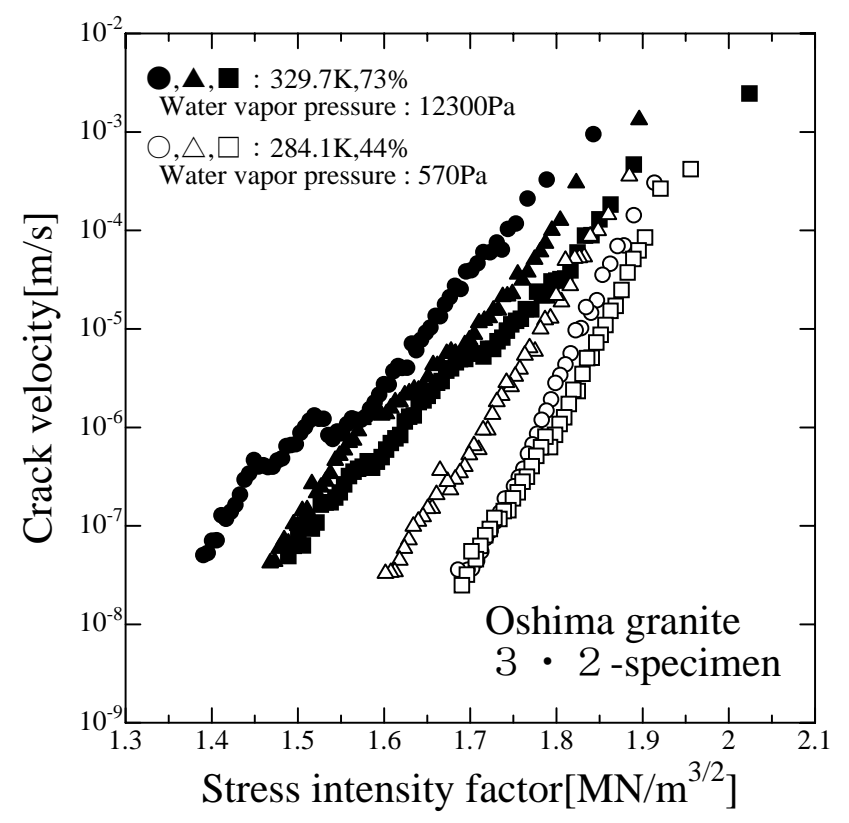

Fig. 8 Relation between the stress intensity factor and the crack velocity for Oshima granite ( $3 \cdot 2$-specimen).

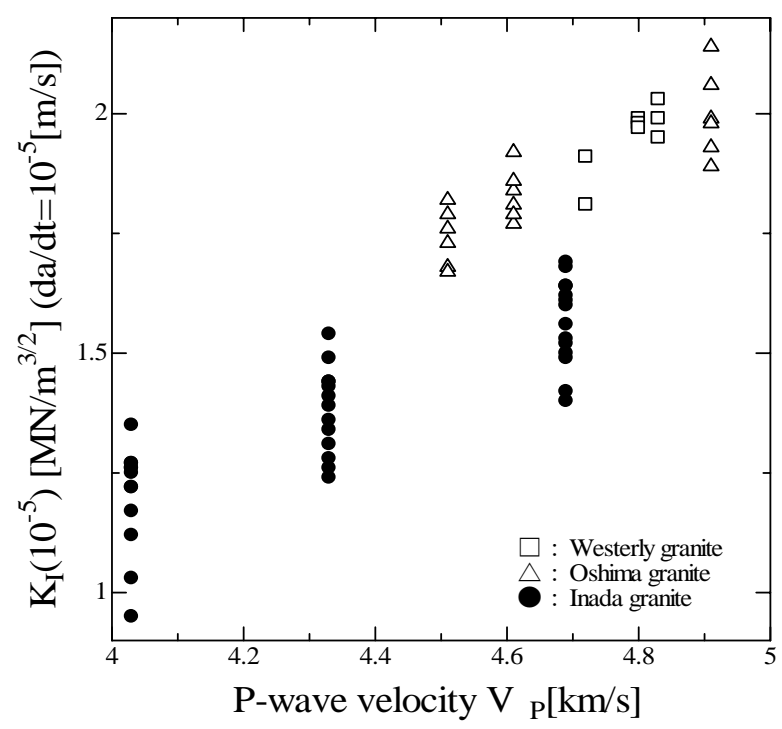

Fig. 9 Relation between the P-wave velocity in the crack opening direction and the stress intensity factor at $\mathrm{d} a / \mathrm{d} t=10^{-5}[\mathrm{~m} / \mathrm{s}]$. 


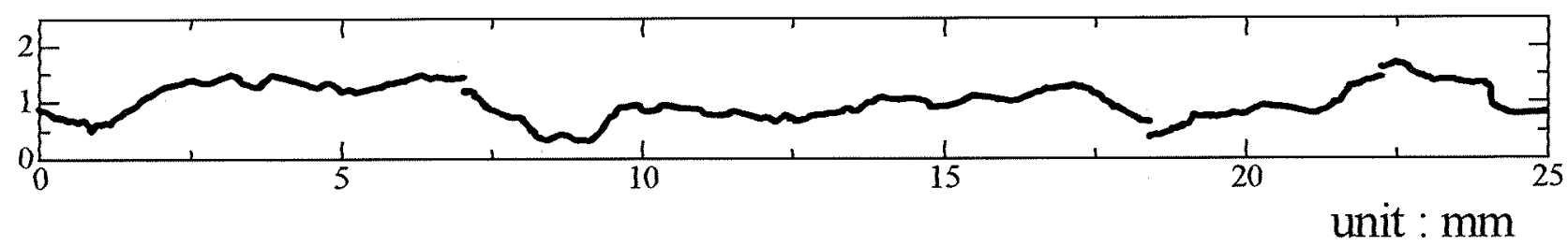

Fig. 10 Crack path in a DT specimen of Oshima granite. Width of this figure is $25 \mathrm{~mm}$.

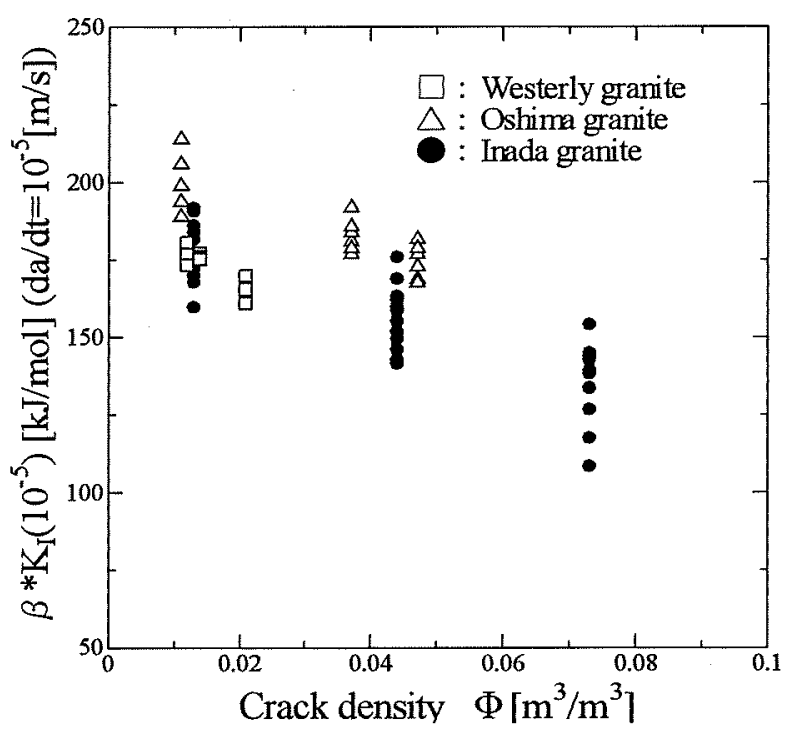

Fig. 11 Relation between the crack density and the energy applied to the crack tip at $\mathrm{d} a / \mathrm{d} t=10^{-5}[\mathrm{~m} / \mathrm{s}]$.

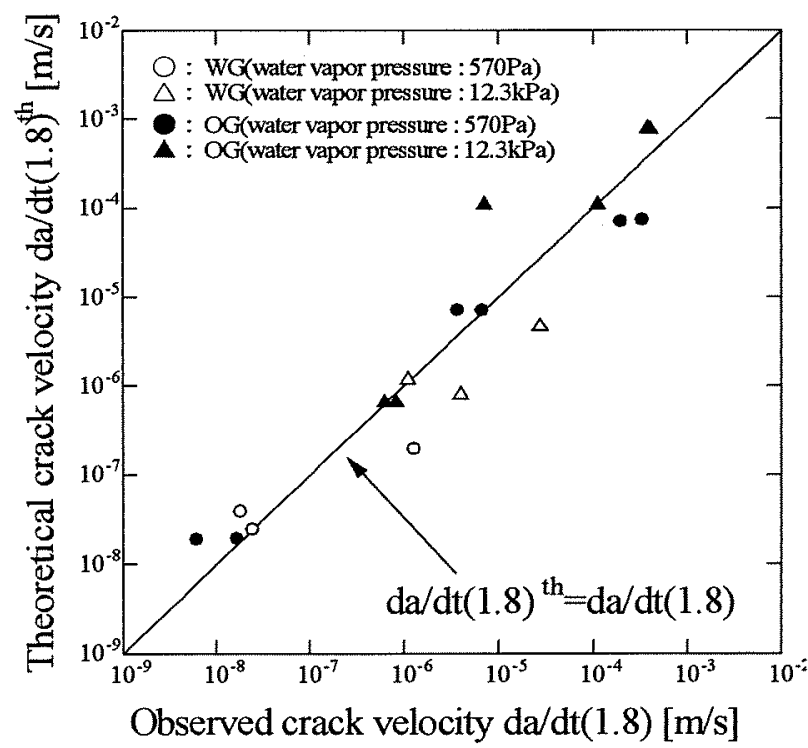

Fig. 12 Comparison between theoretical crack velocity and observed crack velocity for granite. OG means Oshima granite, and WG means Westerly granite. 


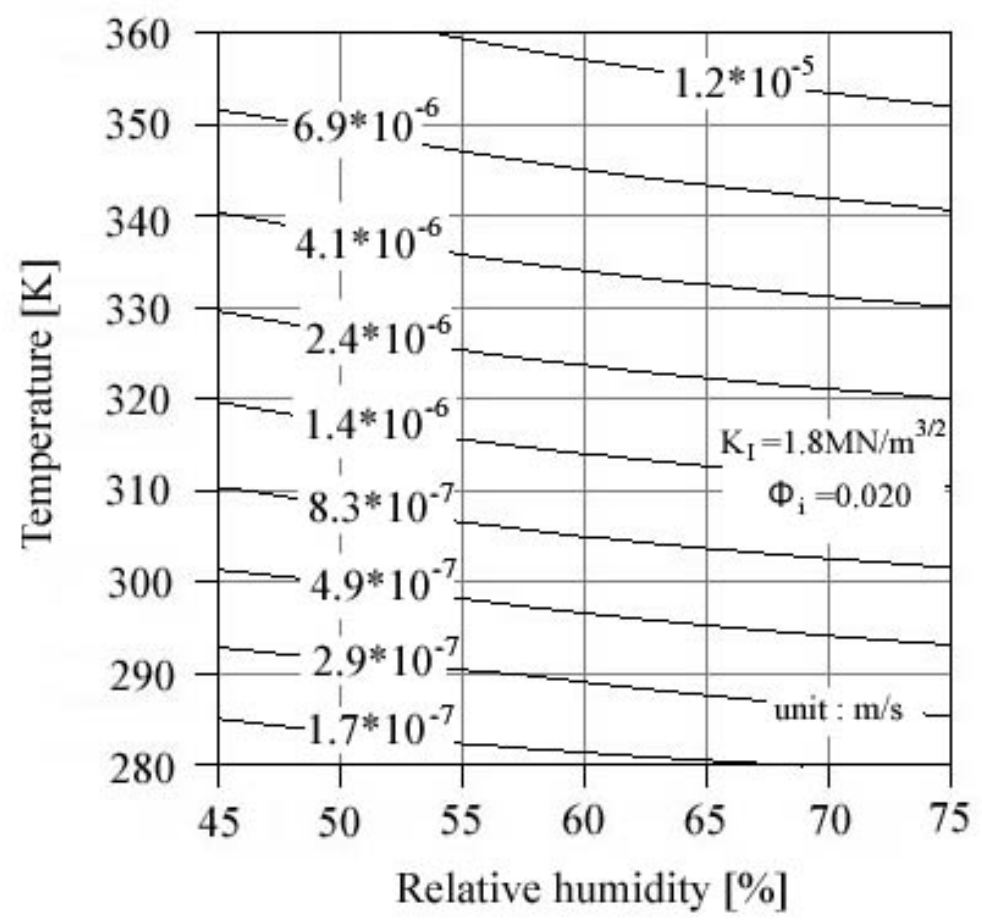

(a)

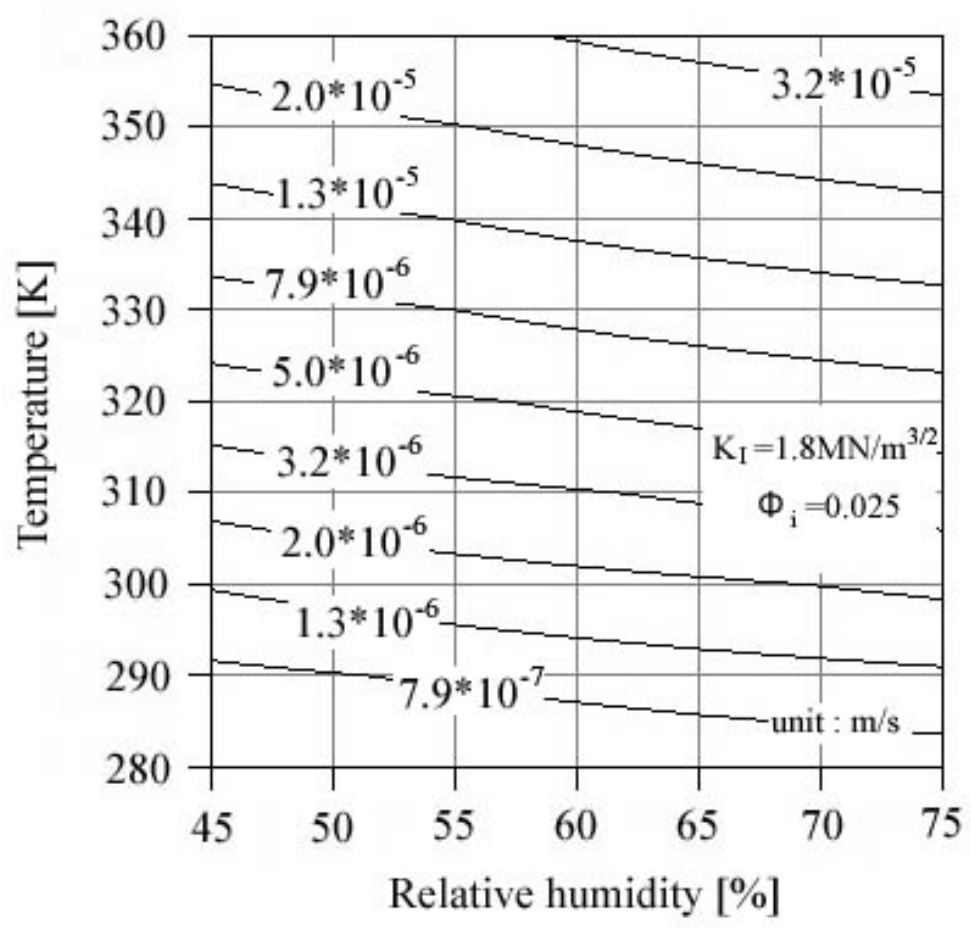

(b)

Fig. 13 Theoretical crack velocity under various temperatures and relative humidity for granite. Stress intensity factor is $1.8 \mathrm{MN} / \mathrm{m}^{3 / 2}$.

(a) : Crack density is 0.020., (b) : Crack density is 0.025 . 


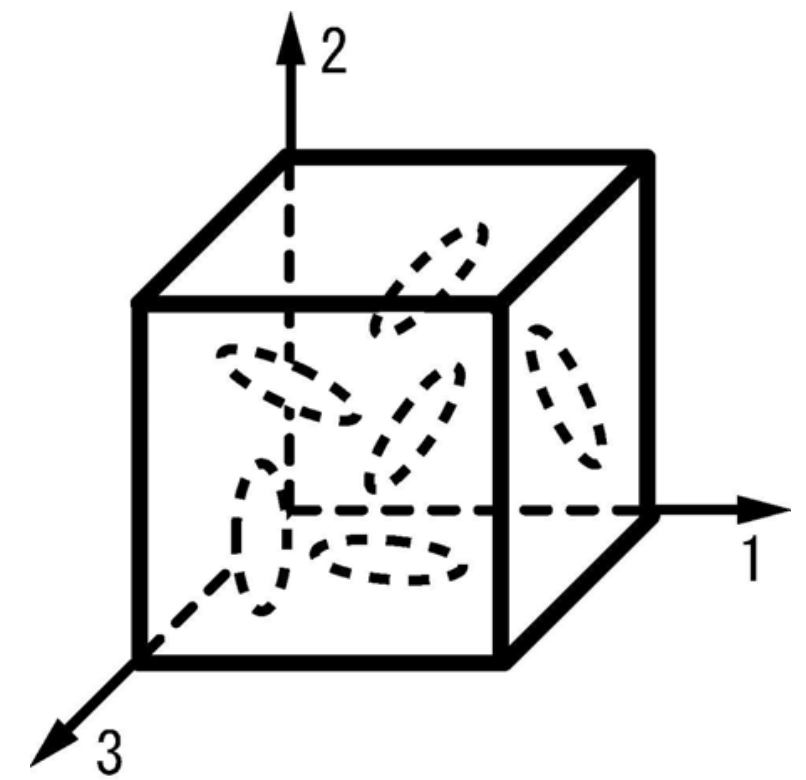

(a) : Type 0

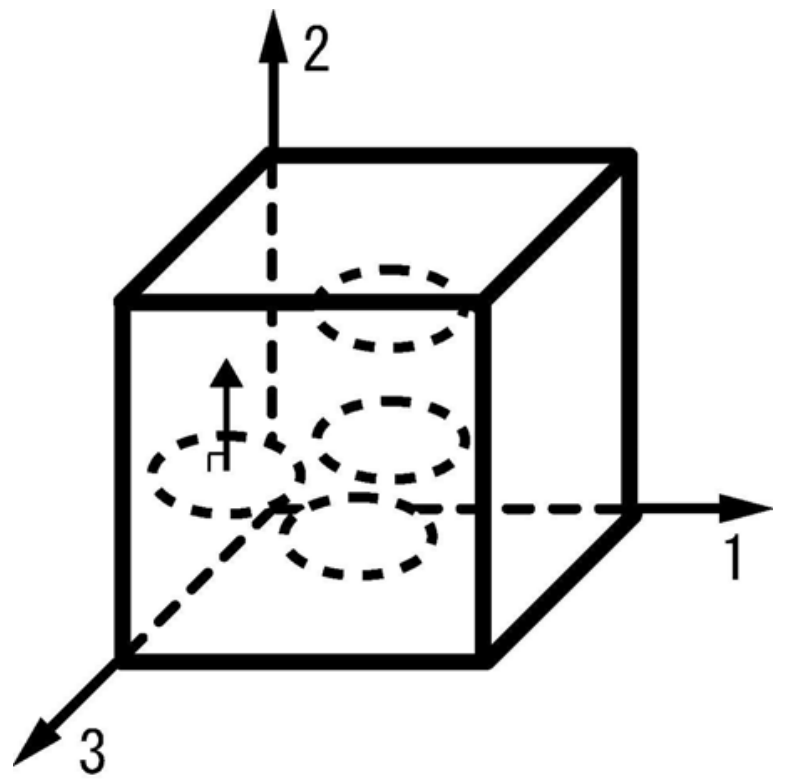

(b) : Type 2

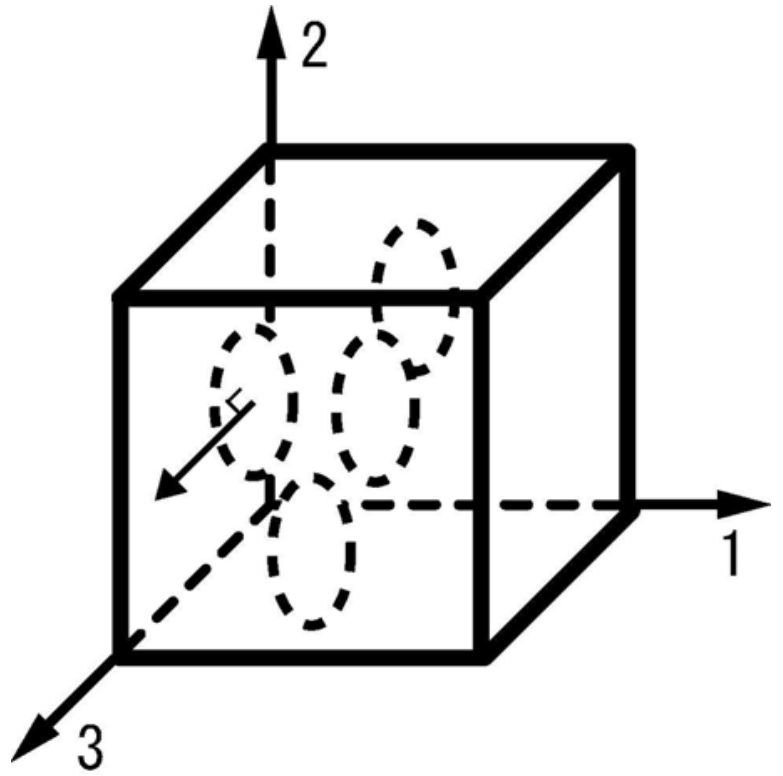

(c) : Type 3

Fig. A.1 Illustrations of the microcrack distribution model. The model of (a) type $0:$ randomly oriented microcracks, (b) type $2:$ microcracks perpendicular to axis-2, and (c) type $3:$ microcracks perpendicular to axis-3 


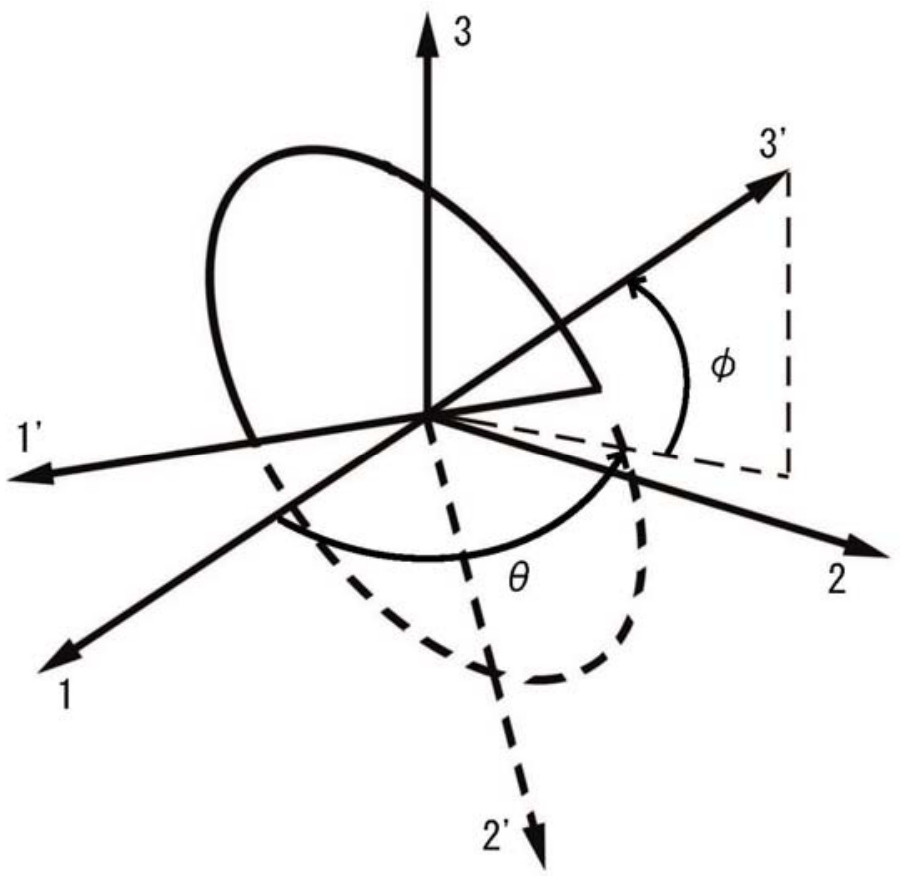

Fig. A.2 Definition of the coordinate system of a penny-shaped crack.
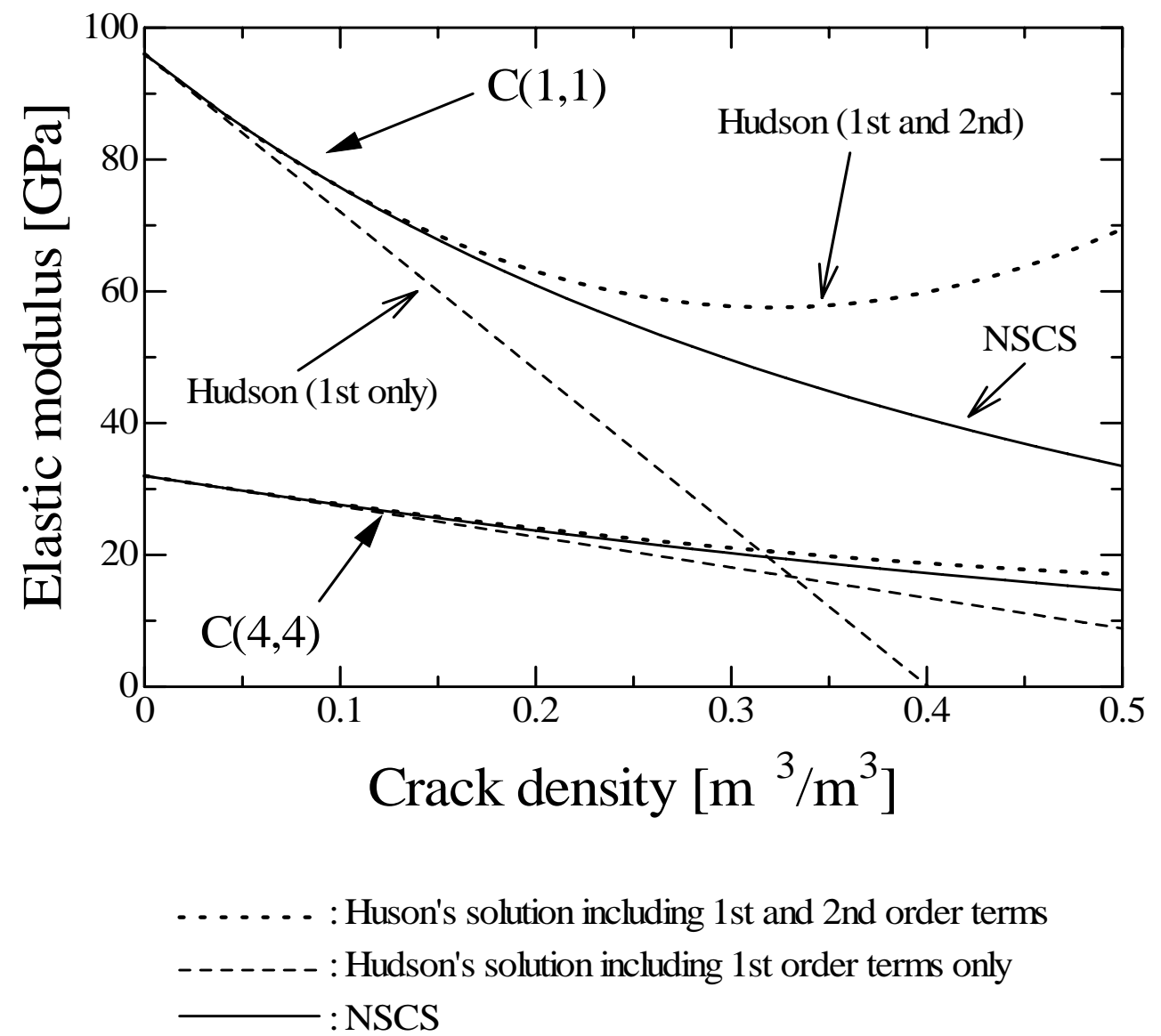

Fig. A.3 Relation between the elastic constants and the crack density of randomly oriented microcracks. 


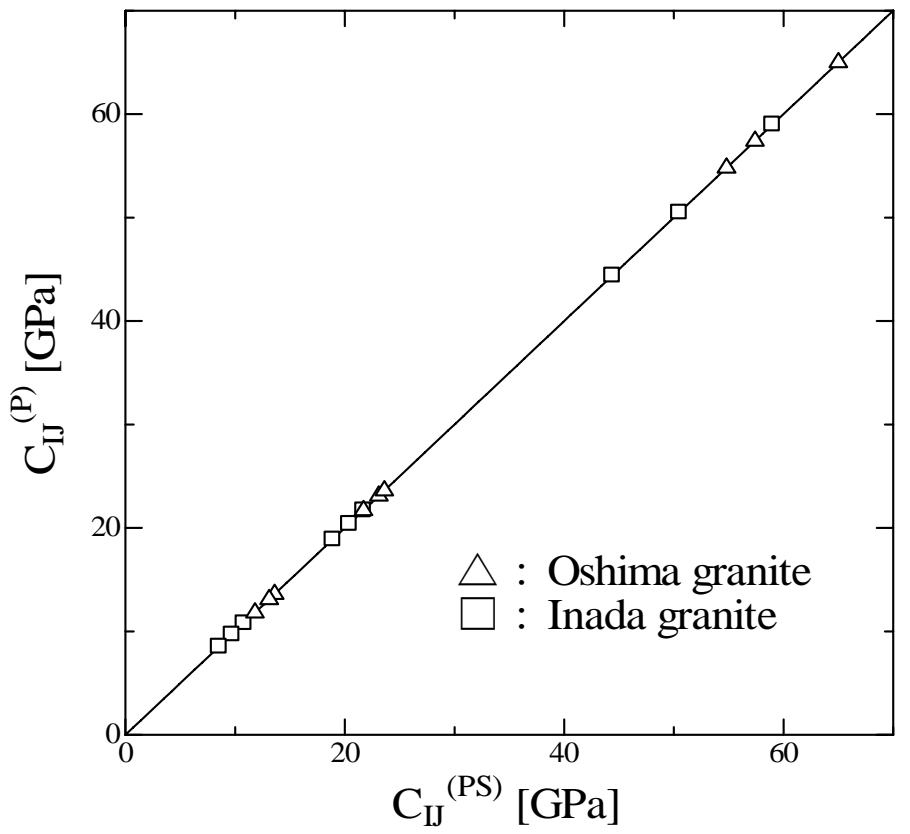

Fig. A.4 Relation between $C_{I J}^{(\mathrm{PS})}$ estimated from P- and S-wave velocities and $C_{I J}^{\left({ }^{(P)}\right)}$ estimated from P-wave velocities. 